Investigações acerca do comportamento bifásico da razão testosterona / cortisol em exercício físico agudo

An approach to the biphasic behavior of the testosterone / cortisol ratio in acute physical exercise

São Paulo

2016 


\title{
Investigações acerca do comportamento bifásico da razão testosterona / cortisol em exercício físico agudo
}

\author{
An approach to the biphasic behavior of the \\ testosterone / cortisol ratio in acute physical exercise
}

Dissertação apresentada ao Instituto de Biociências da Universidade de São Paulo, para a obtenção de Título de Mestre em Ciências, na Área de Fisiologia Geral.

Orientador(a): José Guilherme de Souza Chaui Mattos Berlinck

Exemplar corrigido. $O$ original encontra-se disponível para consulta no Instituto de Biociências da USP.

São Paulo 
De Luccia, Thiago Paes de Barros

Investigacões acerca do comportamento bifásico da razão testosterona / cortisol em exercício físico agudo.

Número de páginas: 75

Dissertação (Mestrado) - Instituto de Biociências da Universidade de São Paulo. Departamento de Fisiologia Geral.

1. Razão Testosterona / Cortisol 2. Exercício físico agudo. Universidade de São Paulo. Instituto de Biociências. Departamento de Fisiologia Geral.

Comissão Julgadora:

Prof(a). Dr(a).

$\operatorname{Prof}(a) . \operatorname{Dr}(a)$

$\operatorname{Prof(a).~Dr.(a).~}$

Orientador: José Guilherme de Souza Chaui Mattos Berlinck 


\section{Epígrafe}

“(...) O correr da vida embrulha tudo.

A vida é assim: esquenta e esfria,

aperta e daí afrouxa,

sossega e depois desinquieta (...)”

João Guimarães Rosa, Grande Sertão: Veredas

(Rio de Janeiro: Nova Fronteira, 2001. p.334.) 


\section{Agradecimentos}

Agradeço à minha família e aos amigos pelo apoio neste percurso.

Agradeço ao meu orientador José Guilherme de Souza Chaui Mattos Berlinck pela sabedoria compartilhada nestes anos de orientação.

Agradeço ao diretor técnico do Laboratório Jablonka Medicina Diagnóstica, Fernando Jablonka, pelas orientações técnicas sobre as análises hormonais e pela participação neste estudo.

Agradeço aos meus colegas de laboratório que muito me ajudaram, em especial à Ingrid El Dash e à Vívian El Dash.

Agradeço muito aos voluntários dessa pesquisa pela participação.

Agradeço à Fundação de Amparo a Pesquisa do Estado de São Paulo (FAPESP) pelo apoio financeiro.

Agradeço ao meu tio José Waldson Lucena de Albuquerque pelo incentivo à pesquisa e pelas longas conversas que tivemos nessa vida. 


\section{Sumário}

I. Introdução

1.1 - Razão testosterona / cortisol e saúde ........................................ 8

1.2 - Razão testosterona / cortisol - aspectos fisiológicos ................... 9

1.3 - Razão testosterona / cortisol no esporte .................................... 16

$\begin{array}{ll}\text { II. Objetivos } & 19\end{array}$

2.1 - Enunciado do problema ........................................................... 19

2.2 - Hipóteses específicas de trabalho ............................................. 19

2.3 - Objetivos específicos .............................................................. 19

III. Materiais e Métodos 20

3.1 - Uma visão geral do protocolo experimental ................................ 20

3.2 - Níveis hormonais ................................................................ 20

3.3 - Grupos experimentais ......................................................... 22

3.4 - Potência do exercício .................................................................. 23

3.5 - Dias experimentais ............................................................ 24

3.6 - Variáveis complementares ...................................................... 25

3.7 - Manutenção da frequência cardíaca alvo .................................... 25

3.8 - Abordagens estatísticas ........................................................... 26

IV. Resultados 30

4.1 - Resultados dos ajustes metodológicos ........................................ 30

4.2 - Resultados brutos ................................................................. 34

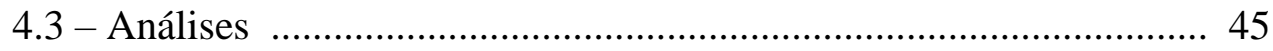

$\begin{array}{ll}\text { V. Discussão } & 50\end{array}$

5.1 - Discussão direcionada às perguntas do estudo ............................. 50

5.2 - Discussão geral sobre os resultados ……..................................... 53

5.3 - Hipótese do hormônio livre ...................................................... 55

5.4 - Ritmos circadianos .............................................................. 56

$\begin{array}{ll}\text { VI. Conclusões } & 57\end{array}$ 
VII. Resumo e Abstract

VIII. Referências Bibliográficas

60

\section{Lista de abreviaturas e siglas}

ACTH: corticotropina.

CBG: globulina ligadora de cortisol.

CRH: hormônio liberador de corticotropina.

$\mathrm{FC}_{\text {max }}$ : frequência cardíaca máxima.

$\mathrm{FC}_{\text {rep }}$ : frequência cardíaca de repouso.

FCT: frequiência cardíaca de treinamento.

HHA: eixo hipotalâmico-hipofisário-adrenal.

HHG: eixo hipotalâmico-hipofisário-gonadal.

LH: hormônio luteinizante.

Razão T/C: razão testosterona / cortisol.

SHBG: Globulina ligadora de hormônios sexuais 


\section{I - Introdução}

\section{1 - Razão testosterona / cortisol e saúde}

Atualmente, a associação entre atividade física e promoção de saúde é bem estabelecida (Pate et al., 1995), entendendo aqui atividade física como qualquer movimento corporal produzido pelos músculos esqueléticos, que resulta em gasto energético maior do que o gasto de repouso (Caspersen; Powell; Christenson, 1985). Nesse contexto a atividade física pode ser ocupacional, esporte, etc. No que se refere ao exercício físico (também uma atividade física, porém planejada, estruturada e repetitiva com finalidade de melhoria ou de manutenção da aptidão física), embora essa atividade possa ser benéfica, ela também pode acarretar problemas de saúde tanto em homens como em mulheres. As respostas fisiológicas ao exercício físico podem ser classificadas como agudas e crônicas e hormônios como a testosterona e o cortisol podem ser utilizados na avaliação de alterações metabólicas causadas por este tipo de atividade (Mastorakos, 2005).

Na fisiologia do esporte, a razão testosterona / cortisol (razão T/C) tem sido usada para analisar o balanço entre processos anabólicos e catabólicos. Entendendo a testosterona como promotora de efeitos anabólicos e o cortisol como promotor de efeitos catabólicos, a razão T/C tem sido considerada como um marcador das síndromes de supra-alcance (overreaching) e de sobretreinamento (overtraining) (estados em que os atletas experimentam um declínio no desempenho esportivo, alterações psicológicas e neuroendócrinas, após ou durante determinado treinamento físico). Nesses estados, supostamente, um ambiente interno catabólico estaria presente, associado ao exercício físico.

Adlercreutz et al. (1986), há trinta anos atrás, sugeriram que uma redução superior a 30 \% na razão testosterona / cortisol no plasma (análises hormonais seriadas do indivíduo em repouso durante período de treinamento físico) seria indicativo de sobretreinamento. Este ponto de vista foi criticado, uma vez que se observou que um declínio superior a 30\% na razão T/C nem sempre resulta em uma deterioração do desempenho atlético no decurso de um período de treinamento (Meeusen et al., 2012). No entanto, pesquisadores continuam a considerar a razão T/C como uma variável útil 
na avaliação dos efeitos agudos e crônicos do treinamento atlético, tanto no treinamento de força como no treinamento de resistência (endurance).

Ao considerar respostas agudas, alterações hormonais mais fugazes como a queda superior a 30\% na razão T/C, ocorre em atletas masculinos amadores após corridas de maratona. Tais alterações hormonais tendem a desaparecer nos dias seguintes do exercício extenuante e não se correlacionam com os sinais e sintomas de sobretreinamento. Tais respostas podem variar, dependendo da aptidão física do atleta. Durante uma resposta crônica, os níveis hormonais podem "permanecer alterados" por períodos prolongados e podem servir como guia para a análise mais ampla do treinamento físico (Meeusen, 2012).

Em termos de aspectos médicos, os níveis baixos de testosterona podem ser indicativos de má saúde em homens. Níveis extremos de andrógenos circulantes, sejam altos ou baixos, podem ter efeitos negativos sobre a saúde da mulher. Em um estudo prospectivo de base populacional de doença cardíaca crônica relacionada ao "estresse" em homens, uma alta razão entre cortisol e testosterona mostrou forte associação positiva com os componentes da síndrome de resistência à insulina (Smith, 2005). É importante notar que neste último estudo citado, avaliou-se a razão cortisol / testosterona e não a razão T/C. O nível baixo de testosterona endógena em homens foi considerado fator de risco para todas as causas de mortalidade, segundo meta-análise de Araujo et al. (2011). Nas mulheres, o hipercortisolismo crônico foi associado com a amenorréia induzida pelo exercício físico. Resultados das análises da densidade mineral óssea nesse grupo, mudaram a ideia de que a amenorréia de atletas seria um evento benigno, ligando esse fenômeno à perda óssea prematura associada aos declínios dos níveis de progesterona e estradiol (Drinkwater, 1986). Algumas doenças, tais como a anorexia nervosa e depressão grave, também foram associadas ao hipercortisolismo crônico (Carroll, 2007). No entanto, o hipercortisolismo crônico causado pela atividade esportiva, e seus efeitos na saúde a longo prazo, particularmente no homem, ainda não são bem estudados.

\section{2 - Razão testosterona / cortisol - aspectos fisiológicos}

O envolvimento de uma complexa rede de regulação com alças de retroalimentação, controles cruzados e ritmos circadianos das secreções hormonais, torna a análise 
desses hormônios difíceis, e mesmo a análise de ritmos sazonais destas secreções hormonais é um desafio (Gouarné, 2005).

O cortisol, a principal forma de glicocorticóide em humanos, é um hormônio preponderantemente catabólico secretado pelo córtex adrenal em resposta a demandas físicas e psicológicas. O exercício que exige $60 \%$ ou mais do consumo máximo de oxigênio $\left(\dot{\mathrm{V}} \mathrm{O}_{2 \max }\right.$ ) de um indivíduo por cerca de 45 minutos foi associado ao aumento da secreção de cortisol, tanto em pessoas treinadas como em não-treinadas (Bloom, 1976; Davies, 1973). O cortisol afeta o metabolismo contribuindo para a manutenção dos níveis de glicose no sangue durante o exercício. Faz isso agindo sobre o músculo esquelético e no tecido adiposo para aumentar a mobilização de aminoácidos e lipídios (Galbo, 2001; Wolfe, 2001), bem como pela estimulação da gliconeogênese. Enquanto os níveis de cortisol aumentam durante o exercício, a maioria das mudanças e os efeitos desse hormônio parecem ocorrer durante o período de recuperação, após o exercício (Hackney, 1999). Apesar de se ter o cortisol como um hormônio catabólico no âmbito da fisiologia do esporte, existem, também, efeitos considerados anabólicos deste hormônio, observados em animais como, por exemplo na maturação intestinal de suínos em fase de amamentação (Wu, Flynn e Knabe, 2000). O cortisol pode aumentar a taxa de síntese protéica e ácido ribonucléico (RNA) no fígado, o que se contrapõe ao efeito catabólico nas reservas protéicas em outros tecidos (Margaret, 2014).

A testosterona é considerada como um hormônio anabólico com várias funções importantes em humanos. Nos homens, a testosterona é produzida e secretada pelas células de Leydig dos testículos, principalmente. A testosterona e seu metabólito ativo, dihidrotestosterona (DHT), são os andrógenos mais importantes e exercem efeitos biológicos através de suas frações livres. A testosterona é principalmente inativada no fígado e é excretada nas fezes ou urina. Nas mulheres, as principais fontes de andrógenos provenientes do colesterol são as glândulas suprarrenais, ovários e tecidos periféricos, tais como tecido adiposo, músculo e pele. Kirschner et al. (1972), relataram que, em mulheres jovens, as fontes de testosterona incluem ovários (25\%), suprarrenais (25\%) e conversão periférica (50\%). A testosterona é importante 
para o crescimento e manutenção dos músculos esqueléticos, dos ossos e eritrócitos do sangue (Zitzmann, 2001).

Os neurônios produtores de vasopressina e do hormônio liberador de corticotropina (CRH) do núcleo paraventricular do hipotálamo e os neurônios do complexo lócus ceruleus-noradrenalina-sistema nervoso simpático no tronco cerebral são os controladores centrais do sistema de resposta ao exercício físico, segundo Mastorakos (2005). O exercício físico intenso estimula os eixos hipotalâmico-hipofisário-adrenal (HHA) e hipotalâmico-hipofisário-gonadal (HHG) através de vários mecanismos que não são totalmente compreendidos. O aumento do lactato plasmático e mediadores humorais, tais como interleucinas e angiotensina II têm sido implicados na ativação do eixo HHA durante atividade física intensa (Wittert, 2000). As beta-endorfinas, fatores liberados na circulação durante o exercício intenso, influenciam as funções do hipotálamo, incluindo a regulação da reprodução através do seu efeito inibidor sobre a liberação do hormônio liberador de gonadotropina (GnRH) (Speroff, 1989). Os opióides endógenos (beta-endorfina) e $\mathrm{o}$ ACTH são derivados da proopiomelanocortina, e a estimulação da secreção desses fatores se dá pelo CRH (Young 1985). O CRH, como os opióides, inibe o eixo HHG e o exercício físico estimula a liberação desses fatores (Torpy, 1998).

A interação dos eixos HHG e HHA é intrincada, e difere nos homens e mulheres. A figura 1 mostra essa interação do eixo HHA e eixo HHG apoiada por estudos realizados em diversos animais incluindo humanos. Uma profunda investigação dessa interação foi realizada em mulheres devido à amenorréia induzida pelo exercício (Otis et. al., 1999). 


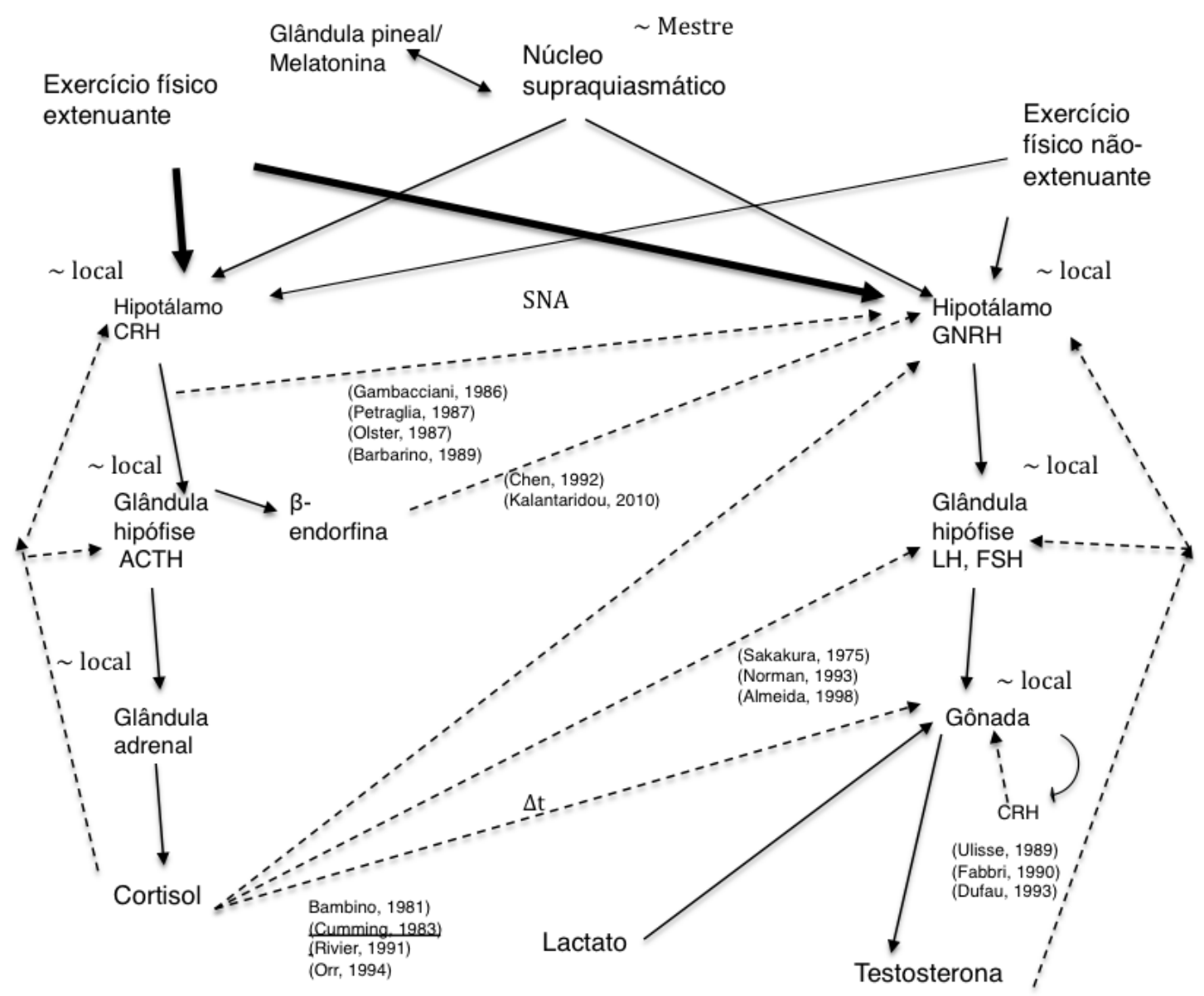

Figura 1: Relação esquemática entre o eixo hipotalâmico-hipofisário-adrenal e o eixo hipotalâmicohipofisário-gonadal. SNA $=$ sistema nervoso autônomo. $\sim$ Mestre $=$ oscilador principal (ritmo circadiano). $\sim$ locais $=$ osciladores locais. Linha tracejada $=$ inibição. Linha contínua $=$ estímulo. $\Delta \mathrm{t}$ : atraso temporal. Autor sublinhado: estudo em seres humanos.

Lu et al. (1997) sugeriram que o aumento nos níveis de testosterona no plasma observados em ratos machos durante o exercício é, pelo menos parcialmente, devido ao efeito da estimulação direta (LH-independente) do lactato na secreção de testosterona nos testículos. Este aumento é mediado por níveis elevados de monofosfato de adenosina cíclico (cAMP) nestes órgãos. Em geral, um aumento nos níveis plasmáticos de testosterona é seguido por estimulação de gonadotropina. No entanto, estudos têm mostrado que os níveis de LH permanecem inalterados após o exercício (Dessypris, 1973; Morville, 1979; Sutton, 1973). Em contraste, Cumming et al. (1986), verificaram aumento no LH após o exercício. Kraemer (1991) mediu os níveis de testosterona no plasma antes, durante, e depois do exercício intenso, e observou que os níveis de testosterona circulantes aumentaram significativamente nos 
homens, mas não nas mulheres. Assim, os mecanismos subjacentes ao aumento induzido por exercício nos níveis de testosterona permanecem sob investigação.

Resultados de estimulação direta por agentes catecolaminérgicos estimularam a produção de testosterona em alguns estudos, o que poderia explicar o rápido aumento dos níveis deste hormônio em resposta a vários estímulos. Um estudo in vitro, utilizando testículos imaturos de hamster dourado, constatou que as catecolaminas (norepinefrina e epinefrina), agindo através receptores alfa e beta-adrenérgicos, são estimuladores fisiológicos potentes da produção de testosterona (Mayerhofer, 1992). Em um estudo com homens saudáveis submetidos a exercício em bicicleta ergométrica, Ježová e Vigas (1981) constataram que o bloqueio de receptores beta por propranolol inibiu a resposta da testosterona ao exercício. De forma contrária, utilizando o modelo de "estresse" de imobilização em ratos (modelo de "estresse" físico e psicológico), a queda acentuada da testosterona sérica é um dos primeiros sinais encontrados em alguns estudos. Tal redução na produção de testosterona induzida pelo "estresse" agudo parece estar relacionada com a inibição das atividades das enzimas esteroidogênicas testiculares (Maric et al., 1996; Stojkov et al., 2012). Em relação a estes últimos estudos citados, parece haver uma resposta divergente da testosterona no modelo de "estresse" agudo de imobilização em ratos comparado à resposta ao exercício físico agudo em humanos.

Segundo alguns estudos, os níveis de testosterona nos homens aumentam em resposta ao exercício físico de força e de resistência submáximos, com concentrações de pico geralmente ocorrendo ao final da atividade física (Wilkerson, 1980). No entanto, alguns estudos têm demonstrado que existe uma correlação negativa entre o cortisol e testosterona em condições específicas, por exemplo nos estudos que avaliaram respostas hormonais em atletas que fizeram maratonas (Dessypris; Kuoppasalmi; Adlercreutz, 1976. França et al., 2006).

Bambino e Hsueh (1981) demonstraram um efeito inibidor direto de altas doses de glicocorticóides sobre a função das células de Leydig dos testículos em ratos. Estes autores notaram uma atenuação na produção de testosterona de acordo com a dose de glicocorticóides e de modo tempo dependente. Além disso, constataram que os glicocorticóides diminuem a quantidade de receptores de LH testiculares. Cumming et 
al. (1983) encontraram uma relação semelhante em seres humanos. Esses pesquisadores especularam que o cortisol poderia interromper a produção de testosterona testicular por perturbar a biossíntese do hormônio. Desta maneira, o termo " $\Delta \mathrm{t}$ " na figura 1 representa a presente hipótese, a ser explicitada mais abaixo, de que o cortisol, uma vez que aumentado devido ao exercício físico, poderia ter um efeito inibitório tardio sobre o eixo HHG.

Rivier et al. (1991), sugeriram que a resposta do sistema hipofisário-testicular ao "estresse" é bifásica, com uma fase estimulante inicial e uma fase subsequente de inibição, a qual é prolongada se o "estresse" é de magnitude suficiente. Os autores também sugerem que as alterações mais imediatas na secreção de LH são mediadas ao nível dos neurônios secretores de GnRH, enquanto que os efeitos a longo prazo sobre o sistema hipofisário-testicular também envolvem mecanismos periféricos, tais como alterações na sensibilidade da resposta da hipófise e das gônadas. Hoffman (2014) também encontrou esse comportamento da testosterona total em resposta ao exercício submáximo de diferentes durações. Exercícios que duraram até 2 horas e 30 minutos resultaram em níveis elevados de testosterona. Após este período, os níveis de testosterona diminuíram, de forma mais acentuada no caso de exercícios que duraram 4 horas.

Em estudo sobre a relação entre o cortisol e a testosterona em homens, em repouso e após o exercício, 30 participantes praticaram 60 minutos de corrida (70 a $75 \%$ do $\left.\dot{\mathrm{V}} \mathrm{O}_{2 \max }\right), 12$ cicloergômetro por 90 minutos $\left(65 \%\right.$ do $\left.\dot{\mathrm{V}} \mathrm{O}_{2 \max }\right)$, e 3 remo durante 60 minutos $\left(65 \%\right.$ do $\left.\dot{\mathrm{VO}}_{2 \max }\right)$ (Brownlee, 2005). Os autores encontraram uma relação negativa entre cortisol e testosterona total (aumento do cortisol e queda da testosterona) após o exercício, enquanto que uma relação positiva foi observada após o exercício entre cortisol e a testosterona livre (período de recuperação, 1 hora após a sessão de exercício físico). Estes autores sugerem que o aumento da testosterona livre após o exercício foi provavelmente devido à contribuição do córtex adrenal ou à dissociação de testosterona livre da globulina transportadora de hormônios sexuais.

Estudos in vitro demonstraram que células de Leydig de ratos também podem secretar CRH em meio de cultura (Dufau, 1993; Fabri, 1990). Em adição aos seus efeitos 
negativos sobre os eixos hormonais centrais, o $\mathrm{CRH}$, neuropéptideo com grande envolvimento nas respostas ao "estresse", exerce um efeito inibidor sobre os testículos, agindo através de receptores de superfície celular das células de Leydig, sendo um regulador negativo do LH, inibindo a produção de testosterona.

No entanto, em ratos, o modelo de "estresse de imobilização" reduziu a testosterona plasmática sem afetar as concentrações de LH no plasma (Charpenet, 1982; Mann, 1990). Um estudo que investigou o efeito do "estresse de imobilização" (imobilização por 3 horas) na esteroidogênese testicular, observou uma redução de $82 \%$ nos níveis de testosterona e níveis significativamente elevados de corticosterona no plasma (Orr, 1994). Este "estresse" inibiu a atividade da 17 alfa-hidroxilase e 17,20-liase, sem afetar a ligação de receptores de LH / hCG. Isto poderia explicar a inibição da redução dos níveis de testosterona (figura 1).

Vários estudos têm mostrado respostas aumentadas de cortisol com concomitante diminuição da testosterona em grupos de corredores masculinos amadores que participaram de maratonas (Boudou, 1987; França, 2006; Karkoulias, 2008). Essa relação divergente entre os dois hormônios parece estar restrita a um período de hipercortisolismo transitório de algumas horas. Nestes grupos de maratonistas, a redução nos níveis de testosterona ocorreu aproximadamente após 4 horas de hipercortisolismo relativo devido ao exercício extenuante. Uma vez que se especula que o cortisol possa ter uma ação direta que reduza a produção de testosterona nos testículos, tal efeito do cortisol sobre as gônadas poderia ser observado após maratonas em corredores amadores do sexo masculino (já que se observou aumentos do cortisol após maratonas e diminuições da testosterona). Isto poderia ser resultado da resposta bifásica do sistema hipofisário-testicular a estímulos causados pelo exercício físico agudo (Rivier, 1991). Primeiramente, a testosterona pode aumentar com os estímulos iniciais da corrida. Após um período, o cortisol, que também aumenta seus níveis no sangue, pode afetar, negativamente, a síntese de testosterona testicular.

No entanto, este tipo de resposta bifásica aguda parece estar relacionado com a extensão da ativação dos eixos hormonais. Estudos têm demonstrado que, em corredores de longa distância, tais respostas hormonais agudas são muito reduzidas 
comparadas com as de corredores de meia distância (Vuorimaa, 2008). Em um estudo que avaliou as respostas hormonais de um grupo de profissionais e corredores masculinos amadores durante temporada de treino de resistência, observou-se que houve um aumento no cortisol dois dias antes de uma maratona apenas no grupo de corredores amadores, enquanto foram observados efeitos anabólicos em profissionais (Bobbert, 2012). Isto pode ser devido a um melhor condicionamento físico, o que pode estar associado com a redução da ativação hipofisária-adrenal em resposta ao volume de treinamento (Luger, 1987). A comparação de usuários crônicos de glicocorticóides a atletas profissionais já foi feita, porém, uma investigação sobre os efeitos do hipercortisolismo crônico em atletas altamente treinados ainda precisa ser aprofundada. Nessa linha, Bonifazi (2009) associou o hipercortisolismo crônico em atletas a uma regulação negativa da isoforma alfa do receptor de glicocorticóide em células mononucleares de sangue periférico.

\section{3 - Razão testosterona / cortisol no esporte}

A razão testosterona / cortisol tem sido amplamente estudada em fisiologia do esporte. Durante o treinamento de força, acredita-se que um ambiente anabólico promova a síntese de proteínas e hipertrofia muscular (fibras musculares do tipo IIb). Acredita-se também que a relação anabolismo / catabolismo possa ser monitorada no treinamento de resistência para melhorar o metabolismo aeróbio dos músculos (fibras musculares do tipo I). Tanto no treinamento de força como no de resistência, é dada atenção aos sinais e sintomas de sobretreinamento.

Ahtiainen et al. (2003), encontraram uma correlação significativa entre o aumento da testosterona causada pelo treinamento físico e a área de secção transversal de certos músculos, sugerindo que aumentos agudos na testosterona podem ter papel importante na hipertrofia muscular. No entanto, sugeriu-se que estas respostas agudas são limitadas em mulheres e pessoas idosas, reduzindo o potencial hipertrófico nestas populações (Hakkinen, 2000; Kraemer, 1993; Nindl, 2001). No que diz respeito a essas diferenças relativas ao sexo dos atletas, Vervoorn (1992) sugeriu que, ao contrário do que foi observado em remadores profissionais do sexo masculino, a razão testosterona livre / cortisol livre não seria um bom indicador do equilíbrio entre processos anabólicos e catabólicos em remadoras profissionais. 
West e Phillips (2012) investigaram as associações entre as respostas hormonais agudas induzidas pelo exercício e os ajustes ao treinamento de força de alta intensidade em uma coorte de 56 jovens do sexo masculino. Alterações no hormônio do crescimento $(\mathrm{GH})$, testosterona livre, IGF-1 e cortisol foram medidos na metade do período de um programa de treinamento de 12 semanas e foram correlacionados com certos marcadores de ajustes fisiológicos de treinamento, incluindo massa corpórea magra, área de secção transversal de fibras musculares e força na perna. Aumentos do GH foram correlacionados positivamente com mudanças nas fibras tipo I em área de secção transversal de fibras musculares. Cortisol e GH, mas não a testosterona e IGF1, foram correlacionados positivamente com o aumento da área de fibras do tipo II. Aumentos no cortisol foram positivamente correlacionados com a mudança da massa corpórea magra de todo o corpo. Nenhum dos hormônios foi associado com a alteração da força na perna. Estes investigadores sugerem que um ambiente interno com elevados níveis de "hormônios anabólicos" não deve ser associado com a hipertrofia muscular ou ganhos de força. Os aumentos de testosterona após um treinamento de força, por exemplo, podem significar uma resposta fugaz ao exercício físico não correlacionada a ganhos hipertróficos (Oeste, 2009; Phillips, 2011; West, 2012).

Embora as respostas hormonais anabólicas ao exercício físico não tenham sido correlacionadas com ganhos em fibras musculares em alguns estudos (West, 2012; Oeste, 2009), algumas pesquisas têm mostrado associação de maiores níveis de testosterona com a motivação e a disposição de competir (Crewther, 2013), bem como a melhoria do desempenho neuromuscular agudo em populações de atletas (Crewther, 2012).

Em consenso atual sobre o sobretreinamento, sugere-se que a razão T/C diminua em relação à duração e à intensidade do treinamento, e que esta proporção indique apenas o esforço fisiológico tangível do treinamento. A razão T/C não pode ser utilizada para o diagnóstico das síndromes de supra-alcance e de sobretreinamento (Meeusen et al., 2012). No entanto, estas síndromes podem ser associadas com o ajuste inadequado do eixo hipotalâmico-hipofisário-adrenal e outros eixos hipotalâmicos. Alguns estudos apresentam a ideia de que o sobretreinamento é o fim de um processo que se inicia com uma perturbação, progride para um acerto e, finalmente, acaba com um mal 
ajuste de todos os eixos hipotalâmicos (Urhausen et al., 1995; Urhausen et al., 1998; Meeusen et al., 2004)

O possível hipercortisolismo devido ao treinamento esportivo pode indicar uma condição com efeitos negativos sobre a saúde, por exemplo associado ao sobretreinamento no médio prazo (Duclos, 2007; Kern, 1995) e associado a componentes da síndrome de resistência à insulina no longo prazo (Smith, 2005). Gouarne et al. (2005) não observaram diferença significativas na excreção urinária de $24 \mathrm{~h}$ de cortisol livre em triatletas, em comparação com homens sedentários da mesma idade, num seguimento de dez meses. A excreção de cortisona (forma inativada do cortisol) porém, foi maior nos triatletas. Isso traz a dúvida se os homens bem treinados para algumas modalidades de esportes podem desenvolver um hipercortisolismo crônico, ou apenas possuem uma maior metabolização do cortisol. Ainda assim, nesse estudo, dois triatletas apresentaram a síndrome de sobretreinamento com razão cortisol / cortisona urinária (> 1). Isso indicaria uma menor inativação do cortisol nesses dois atletas em comparação com os outros. Luger et al. (1987) observaram que os corredores altamente treinados mostraram respostas menores do cortisol devido ao exercício em comparação com outros dois grupos (sujeitos moderadamente treinadas e sedentários). Ainda nesse estudo, corredores altamente treinados apresentaram respostas diminuídas do ACTH e do cortisol ao estímulo com CRH ovino, compatível com um estado de hipercortisolismo sustentado (Luger, 1987). Assim, como já mencionado no final da seção 1.2, a associação da excessiva prática de exercício físico com desfechos negativos à saúde relacionados ao hipercortisolismo, especialmente em homens, é uma questão que ainda precisa ser aprofundada. 


\section{II - Objetivos}

\section{1 - Enunciado do problema}

A presente pesquisa visou avaliar como o perfil anabólico / catabólico hormonal se comporta agudamente após evento de exercício físico, tendo em vista dados contraditórios presentes na literatura. De uma maneira geral, com os resultados do presente estudo pretendeu-se um melhor entendimento dos processos fisiológicos associados ao perfil anabólico / catabólico frente ao exercício físico agudo, tentando lançar luz na ambiguidade que hoje se tem na literatura acerca das respostas de tal perfil.

As seguintes questões foram propostas:

(1) existe um componente bifásico na resposta da relação $T / C$ após evento de exercício físico agudo?

(2) existe uma relação deste componente com a intensidade do exercício físico agudo?

(3) existe uma relação deste componente com o tempo de exercício físico agudo?

(4) existe diferença no comportamento deste componente em relação a grupos treinados e não treinados?

\section{2 - Hipóteses específicas de trabalho}

1. A relação $\mathrm{T} / \mathrm{C}$ pode ser alterada agudamente em função da demanda energética total durante um período, e apresenta uma resposta bifásica.

2. Essa resposta bifásica hormonal pode ocorrer diferentemente em indivíduos treinados e não-treinados, na medida em que a ativação dos eixos HHA e HHG pode ser modulada pelo estado de treinamento do indivíduo.

\section{3 - Objetivos específicos}

Responder as questões colocadas mais acima submetendo voluntários treinados e nãotreinados a sessões de exercício físico agudo (corrida em esteira ergométrica). 


\section{III - Materiais e Métodos}

\section{1 - Uma visão geral do protocolo experimental}

Experimentos:

Todos os experimentos foram realizados utilizando a corrida em esteira ergométrica para proporcionar um maior controle experimental. Os tempos das sessões de exercício físico de corrida foram determinados de acordo com as observações dos fenômenos relacionados às alterações de testosterona feitas por Hoffman (2014; ver Introdução), e descrito mais abaixo.

As coletas das amostras de saliva nos dias das corridas foram realizadas em horários fixos para evitar variações circadianas [8:00 (primeira coleta); entre 8h30min e 9h00min (segunda coleta) e 11:h15min (coleta tardia)]; tempos de coletas estabelecidos a partir da análise dos resultados de um teste piloto realizado previamente com um voluntário treinado e outro não-treinado. Em dia em que os voluntários não praticaram exercício físico, foram coletadas amostras basais às 08:00 e às 11:00.

\section{2 - Níveis hormonais}

\subsection{1 - Mensuração do cortisol e da testosterona.}

A saliva é um fluido aquoso conseguido facilmente e de forma não-invasiva, que pode ser usado para se acessar as concentrações de uma ampla gama de moléculas, por exemplo as moléculas de alguns hormônios (Kiess e Pfaeffle, 2007). No caso da testosterona e do cortisol, as frações livres destes hormônios podem ser mensuradas na saliva.

O fluxo de componentes do plasma para a saliva pode envolver vários processos, por exemplo: ultrafiltração por meio das junções em hiato entre as células secretoras (moléculas de baixo peso molecular como íons, água, e certos hormônios); transporte seletivo através de difusão passiva de moléculas lipofílicas (hormônios esteróides); transporte ativo através de canais iônicos; e de bombeamento ativo de íons $\mathrm{Na}^{+}$com entrada concomitante de água (Nunes e Macedo, 2013).

Proteínas séricas e globulinas que se ligam aos hormônios esteróides são 
moléculas grandes que não passam através das membranas celulares das glândulas salivares. Assim, apenas as frações livres desses hormônios presente no plasma podem passar para a saliva, e um estudo mostra haver concordância das frações livres plasmáticas destes hormônios com as concentrações salivares (Vining, McGinley e Symons, 1983).

As dosagens hormonais (testosterona e cortisol) em nosso estudo foram realizadas em amostras de saliva pelo Laboratório Jablonka Medicina Diagnóstica de São Paulo. Os procedimentos de análise laboratorial foram acompanhados em parte pelo pesquisador para a verificação da adequação dos resultados.

As amostras foram colhidas através de salivação passiva direta em tubo coletor e armazenadas em sacola térmica a 10 graus Celsius e posteriormente em congelador (20 graus Celsius).

Os seguintes cuidados foram seguidos antes das coletas:

-Não escovar os dentes, comer ou ingerir líquidos por 1 horas antes da coleta;

-Não realizar tratamento dentário 24 horas antes da coleta do exame;

-Imediatamente antes da coleta, lavar a boca através de bochechos leves usando água.

As dosagens hormonais foram feitas por metodologia de ensaio de imunoadsorção ligado a enzima (ELISA). O kit comercial de ELISA utilizados no Laboratório Jablonka Medicina Diagnóstica foi o DiaMetra SRL - Itália para hormônios salivares.

Nos dias dos ensaios, as amostras congeladas foram descongeladas completamente e homogeneizadas. O ensaio utiliza placa para microtulação tipo ELISA com poços revestidos com anticorpos anti-cortisol. O princípio do ensaio, consiste na competição do cortisol das amostras de saliva (antígeno) com o cortisol antigênico conjugado com a enzima horseradish peroxidase pela ligação aos limitados anticorpos anti-cortisol revestindo os poços da placa. Assim, após período de incubação das amostras de saliva nos poços da placa conjuntamente com o cortisol antigênico conjugado com a enzima horseradish peroxidase, é realizada lavagem para se separar as porções ligadas e as porções livres dos antígenos. Posteriormente, a enzima horseradish peroxidase da 
porção ligada aos anticorpos reage com o substrato $\left(\mathrm{H}_{2} \mathrm{O}_{2}\right)$ e o substrato tetrametilbenzidina (TMB) gerando uma coloração azulada, que depois se torna amarelada com a solução de paragem ácida $\left(\mathrm{H}_{2} \mathrm{SO}_{4}\right)$. A leitura da absorbância da microplaca foi feita em espectrofotômetro a partir de fonte luminosa com comprimento de onda de $450 \mathrm{~nm}$. A quantidade cortisol-peroxidase detectada, que se expressa pela intensidade da cor, é inversamente proporcional à quantidade de cortisol presente em cada amostra. Finalmente o cortisol é calculado através de curva de calibração conhecida e interpolação dos dados. Quanto à performance do ensaio, segundo o manual do mesmo, existe uma variação intra-ensaio $\leq 10 \%$ e variação inter-ensaio $\leq 8,3 \%$.

Metodologia muito semelhante foi usada para os ensaios de testosterona, sendo que neste caso, a microplaca apresenta o anticorpo anti-testosterona. A testosterona também é calculada através de uma curva de calibração. Quanto à performance do ensaio, segundo o manual do mesmo, existe uma variação intra-ensaio $\leq 8,0 \%$ e variação inter-ensaio $\leq 13,2 \%$.

\subsection{2 - Horários de coleta}

Amostras basais foram colhidas nos horários das 08:00 e 11:00 da manhã, em dia em que o voluntário não praticou atividade física. Nos dias das sessões de corrida, foram colhidas 3 amostras para análises de testosterona e cortisol [pré-teste (08:00), pósteste imediato (horário variável) e pós-teste tardio (11:15)].

\section{3 - Grupos experimentais}

Não-treinados (NT): indivíduos que não praticam exercício físico de corrida regularmente.

Treinados (T1 e T2, ver abaixo): atletas amadores que fizeram provas de corrida de longa distância (meia maratona ou maiores, pelo menos 1 prova no último ano) e que praticam atividade de corrida com esforço físico moderado a intenso por mais de 150 minutos por semana.

Indivíduos por grupo: 6 (total de 18 voluntários).

Foram selecionados somente voluntários do sexo masculino para o estudo. 
Todos os participantes tiveram uma ficha de acompanhamento e um termo de consentimento informado. (Projeto aprovado pelo Comitê de Ética do IB-USP, CAAE 12937713.0.0000.5464).

\section{4 - Potência do exercício}

A demanda energética do exercício físico realizado é o marco natural da intensidade dessa atividade. Numa ampla faixa de demanda metabólica, há uma relação linear desta com a frequência cardíaca (FC). Assim, a FC opera como um estimador indireto da intensidade de exercício físico, e a estimativa da demanda metabólica via FC é denominada de "método da frequência cardíaca" (Green, 2011). A partir deste conceito, as perguntas delineadas mais acima foram abordadas através de dois ângulos:

a) Efeito da intensidade do exercício físico em tempo fixo: obtido através de diferentes FCs alvo (FCT) a partir da fórmula proposta por Karvonen (1957) [ $\left.\left.\mathrm{FCT}=\%_{\mathrm{ACM}} \cdot\left(\mathrm{FC}_{\max }-\mathrm{FC}_{\mathrm{rep}}\right)\right]+\mathrm{FC}_{\mathrm{rep}}\right]$ em duas populações diversas (homens treinados e não-treinados). Aqui ACM corresponde a amplitude cardíaca máxima do indivíduo e \% $\%_{\mathrm{ACM}}$ é a porcentagem desta amplitude (diferença entre a $\mathrm{FC}_{\mathrm{Max}}$ e a $\mathrm{FC}_{\mathrm{rep}}$ ). $\mathrm{O}$ cálculo da $\mathrm{FC}_{\max }$ utilizado foi: 220 - idade;

b) Efeito do tempo em gasto fixo: obtido através do produto entre tempo de teste x FC, de modo a obter-se um gasto energético total semelhante, em uma única população (treinados - T2). Como método de estabelecimento da demanda energética total semelhante entre os voluntários, optou-se por fixar um número total de batimentos cardíacos por sessão de corrida: 6300 batimentos totais $\left(\mathrm{B}_{\mathrm{t}}\right)$. A partir desses batimentos cardíacos totais fixos, calcularam-se os tempos de corrida por sessão em $\mathrm{FCT}_{65}$ e $\mathrm{FCT}_{80}$. Tal escolha baseou-se no pressuposto de que a $\mathrm{FC}_{\text {rep }}$ é proporcional à taxa de gasto energético basal $\left(\mathrm{TGE}_{\mathrm{b}}\right)$ de cada voluntário. Assim, pela FCT individual e Bt fixos calcularam-se os tempos de corrida de cada sessão $\left(T_{\mathrm{s}}\right)$ (ver formulações abaixo).

- FC $_{\text {rep }} \propto$ TGE $_{b}$

- $\mathbf{T}_{\mathrm{s}}(\mathbf{F C T} \%)=\mathrm{B}_{\mathrm{t}} /\left[\%_{\mathrm{ACM}} \cdot\left(\mathrm{FC}_{\max }-\mathrm{FC}_{\mathrm{rep}}\right)\right]+\mathrm{FC}_{\mathrm{rep}}=\mathbf{B}_{\mathbf{t}} / \mathbf{F C T} \%$

\section{5 - Dias experimentais}


Dia 0: o voluntário compareceu ao laboratório para um contato primário com o ambiente e modo de operação do experimento. Corridas foram feitas para estabelecimento das velocidades correspondentes às FCs alvo. Nesta fase, buscaramse as frequências cardíacas alvo em certo estado de regime permanente (steady state) de taxa metabólica (potência média fixa). Esta etapa iniciou-se com uma corrida de 10 minutos em velocidade de conforto, e após este período, acertaram-se velocidades que levassem a FC aos parâmetros almejados. A estabilização das frequências cardíacas dentro das janelas alvo $\left(\mathrm{FCT}_{65}\right.$ e $\left.\mathrm{FCT}_{80}\right)$ por 10 minutos de corrida, foi pré-requisito para a participação da pesquisa. Dados antropométricos foram colhidos e instruções quanto à hidratação e à alimentação nos dias prévios aos testes foram dadas.

Nos dias de teste, os voluntários tiveram um período de 10 minutos em repouso antes do início das coletas e corridas, de modo a diminuir eventuais efeitos externos prévios à chegada ao laboratório.

\section{Grupos NT e T1}

Dias 1 e 2: o voluntário comparece ao laboratório para executar uma corrida de 30 minutos em $\mathrm{FCT}_{65}$ e $\mathrm{FCT}_{80}$ (ver Dia-0, acima; as velocidades foram sorteadas de maneira aleatória entre os dias). Durante as corridas, a cada 5 minutos ocorreram ajustes na velocidade de corrida (caso fosse necessário), para que a FC alvo ficasse dentro dos limites pré-definidos.

\section{Grupo T2}

A partir dos dados do Dia-0, calcularam-se os tempos particulares para que todos os voluntários deste grupo tivessem uma demanda energética total semelhante.

Dias 1 e 2: o voluntário compareceu ao laboratório para executar uma corrida pelos tempos particulares seus, determinados acima em FCT $_{65}$ e FCT $_{80}$ (as velocidades foram sorteadas de maneira aleatória entre os dias).

Coletas de amostras de saliva para dosagens hormonais:

- Coleta pré-teste (para determinação da razão $\mathrm{T} / \mathrm{C}=\mathrm{a}$ )

- Coleta pós-teste imediato (para determinação da razão $\mathrm{T} / \mathrm{C}=\mathrm{i}$ )

- Coleta pós-teste tardio (para determinação da razão $\mathrm{T} / \mathrm{C}=\mathrm{t}$ ) 
A partir das razões acima, foram calculados os índices de variação da razão $T / C$ : variação imediata $I=i-a$; variação tardia $T a=t-a$.

\section{6 - Outras variáveis}

Monitorização cardíaca contínua durante as corridas para análise da frequência cardíaca alvo.

- Glicemia capilar em amostra de sangue (ponta de dedo) antes e após as sessões de corrida (aparelho Accu-Chek ${ }^{\circledR}$ Performa, medidor de glicemia).

Estimativa de gordura corpórea, utilizando o método da soma de sete pregas cutâneas proposto por Jackson e Pollock (1978). As medidas das pregas cutâneas foram realizadas com adipômetro manual.

\section{7 - Manutenção da frequência cardíaca alvo}

Regime permanente de corrida.

Uma das primeiras dificuldades encontradas em nosso estudo foi conseguir estabelecer um regime permanente de corrida dentro das denominadas zonas de treinamento. Como não foi avaliado o consumo de oxigênio através de aparato de respirometria, a intensidade do exercício físico foi estimada a partir de frequências cardíacas alvo préestabelecidas. Mesmo sabendo como a FC de cada voluntário se comportaria em cada velocidade de corrida a partir dos dados do dia 0 , foi necessário que houvesse ajustes na velocidade de corrida a cada 5 minutos em busca de se manter a FC constante.

Em relação a essa problemática, podemos citar a questão da deriva cardíaca. Definese deriva cardíaca como um aumento da frequência cardíaca ao longo do tempo durante exercício moderado prolongado de intensidade constante, conjuntamente com uma queda do volume sistólico, que se inicia aproximadamente após 10 minutos de atividade física (Lafrenz et al., 2008. Wingo, Ganio, e Cureton, 2012). Autores observaram que a deriva cardíaca pode ser influenciada por fatores como hipertermia (Gonzalez-Alonso et al., 1998), desidratação (Montain e Coyle, 1992) e deslocamento sanguíneo para a periferia (Rowell et al., 1969). Embora a deriva cardíaca possa ser um problema quando se utiliza a frequência cardíaca como estimador da demanda 
metabólica, estudos como o de Wingo et al. (2012), mostraram que mesmo havendo incremento na FC durante testes em cicloergômetro e caminhada em esteira a $60 \%$ do $\dot{\mathrm{V}} \mathrm{O}_{2 \max }$, o consumo de oxigênio não foi significativamente afetado.

A busca por um regime permanente durante o exercício físico baseado em uma FC constante não é viável do ponto de vista estrito do termo. Assim, optou-se por zonas de FC alvo com uma janela de variação baseada nas frequências cardíacas de treinamento. Em nosso caso, considerou-se o voluntário em regime permanente aquele que, durante o exercício físico proposto, permaneceu com uma variação de frequência cardíaca alvo de $\pm 7 \%$. Essa variação foi estabelecida a partir dos resultados de teste piloto realizado com um indivíduo treinado e outro não treinado buscando metas de regime permanente. Essa variação de $7 \%$ equivale a \pm 10 batimentos cardíacos.

\section{8 - Abordagens estatísticas}

\subsection{1 - Construção de intervalos de confiança das amostras nos indivíduos.}

As mensurações dos níveis hormonais de cortisol e testosterona apresentam variações amplas num mesmo indivíduo, e, portanto, duas amostras colhidas com pequeno intervalo podem apresentar valores enganadoramente diferentes. Logo, para se efetuarem comparações válidas, é necessário a obtenção de intervalos de confiança nas amostras. Contudo, o número de amostras por indivíduo foi restrito devido a dois fatores. Em primeiro lugar, existe a grande dificuldade em obter voluntários para realizarem mais do que duas corridas no laboratório, sob as condições prescritas e controladas do experimento. Assim, cada voluntário realizou somente um conjunto de 2 experimentos, e mais uma coleta que foi denominada basal. Em segundo lugar, o custo por experimento é bastante elevado para a determinação dos níveis hormonais. Assim, a opção foi, para se ter um grupo amostral maior, um número de amostras menor por indivíduo.

Frente a estas limitações, utilizou-se o seguinte racional para a obtenção de intervalos de confiança e posterior comparação.

Para cada indivíduo i $(\mathrm{i}=1,2,3 \ldots 18)$ há três amostras basais obtidas em dias diferentes às 8 horas da manhã. Estas amostras são independentes de se o indivíduo iria ou não realizar esforço físico e qual (sem esforço, 65\% ou 80\%). A partir destas 
três amostras, de agora em diante denominadas por "basal", construiu-se um intervalo de confiança b para cada indivíduo i e cada hormônio h $(\mathrm{C}$ ou $\mathrm{T})$ :

$b_{i, h}=1,96 \cdot \frac{s_{i, h}}{\sqrt{3}}=1,13 \cdot s_{i, h}$

Sendo s o desvio padrão obtido para as três amostras do basal. Tendo-se, então, uma certa amostra $A_{i, h, j}$ e uma outra $A_{i, h, k}$, estas são consideradas iguais se a amostra $k$ pertencer ao intervalo da amostra $\mathrm{j}$ :

$A_{i, h, k} \in\left\{A_{i, h, j}-b_{i, h}, A_{i, h, j}+b_{i, h}\right\}$

Se $A_{i, h, k}$ menor que $A_{i, h, j}-b_{i, h}$, então será dito que houve diminuição do hormônio $h$ na condição $\mathrm{k}$. Se $\mathrm{A}_{\mathrm{i}, \mathrm{h}, \mathrm{k}}$ maior que $\mathrm{A}_{\mathrm{i}, \mathrm{h}, \mathrm{j}}+\mathrm{b}_{\mathrm{i}, \mathrm{h}}$, então será dito que houve aumento do hormônio h na condição k. Se $\mathrm{A}_{\mathrm{i}, \mathrm{h}, \mathrm{k}}$ pertencer ao intervalo acima definido, então será dito que não houve alteração do hormônio h na condição k.

3.8.2 - Razão T/C. Para a razão T/C, devido à necessidade de se propagar erro para a construção do intervalo de confiança da fração, e dado que o erro estimado já contém uma imprecisão grande, a propagação de erro (que, em tal caso seria obtido através da soma das variâncias) levaria à impossibilidade de surgirem quaisquer diferenças. Desta maneira, decidiu-se por não propagar erro e tomar-se cada fração $\mathrm{T}_{\mathrm{i}, \mathrm{k}} / \mathrm{C}_{\mathrm{i}, \mathrm{k}}$ como sendo um valor sem incerteza associada. Tais valores foram, então, utilizados diretamente nos testes estatísticos.

\section{$\underline{3.8 .3 \text { - Análise das populações NT, T1, T2 a partir dos resultados individuais }}$} classificatórios em diminuição, aumento ou sem alteração. As classificações (diminuição, aumento, sem alteração) foram utilizadas em testes binomiais para responder as duas seguintes questões:

(1) Há aleatoriedade em haver algum tipo de alteração (diminuição, aumento) e não haver alteração? Esta pergunta foi abordada através da quantidade de "não alterações" num dado conjunto de indivíduos, tomando-se as probabilidades $\mathrm{p}, \mathrm{q}$ da distribuição binomial como $\mathrm{p}=\mathrm{q}=50 \%$ (ou seja, qual a probabilidade de se obter a quantidade de "alterações" e de "não alterações" se estas tivessem uma chance aleatória de ocorrer);

Caso a questão (1) tenha resultado negativo (ou seja, a probabilidade de o resultado ser oriundo do acaso é menor que 0,05$)$, passa-se à próxima: 
(2) Há aleatoriedade nas alterações (ou seja, diminuir e aumentar têm probabilidades similares a 50\%)? O mesmo tipo de teste binomial da pergunta (1) foi, então, realizado.

Note que estas questões são de caráter geral, ou seja, está-se apenas mostrando qual a abordagem estatística que foi empregada para responder algumas das perguntas específicas, colocadas mais abaixo, estas, sim, dedicadas ao problema em foco no presente estudo.

De maneira a deixar clara qual a metodologia de análise utilizada em cada uma das perguntas abaixo, utiliza-se o termo comparação binomial para indicar que a pergunta foi abordada via teste binomial (descrito logo acima) e o termo comparação direta para indicar que foi utilizado Teste-t (simples ou pareado) nos dados brutos para abordar a pergunta. De fato, as perguntas (0) foram abordadas via comparação binomial e as perguntas (1-4) foram abordadas via comparação direta. As perguntas (0) dizem respeito ao quesito mais básico do presente estudo, ou seja, se ocorre alteração significativa no cortisol e/ou na testosterona em decorrência dos protocolos de exercício propostos. Já as perguntas (1-4) dizem respeito ao foco do estudo, ou seja, como se comporta a razão T/C, imediata e tardia, frente aos diferentes protocolos nos diferentes grupos de indivíduos.

Pergunta (0) "há alteração da concentração dos hormônios em decorrência da atividade física proposta?"

(0a) comparação binomial da alteração classificatória entre pré e pós imediato.

(0b) comparação binomial da alteração classificatória entre basal de 11:00 e pós-tardio.

Pergunta (1) "existe um componente bifásico na resposta da relação T/C após evento de exercício físico agudo?" - Comparação direta pareada entre os valores I e Ta para cada condição de exercício (i.e., $65 \%$ e $80 \%$ ).

$\mathrm{I}_{65} \mathrm{x}$ Ta65

$\mathrm{I}_{80} \mathrm{X} \mathrm{Ta}_{80}$

Pergunta (2) "existe uma relação deste componente bifásico com a intensidade do exercício físico?" - Comparação direta pareada dos valores I e Ta entre os obtidos a 
$65 \%$ e os obtidos a $80 \%$.

$\mathrm{I}_{65} \mathrm{X} \mathrm{I}_{80}$

$\mathrm{Ta}_{65} \mathrm{x} \mathrm{Ta}_{80}$

Pergunta (3) "existe uma relação deste componente com o tempo de exercício físico?" - Comparação direta simples entre T1 e T2, a 65\% e a 80\%, separadamente.

$$
\begin{aligned}
& \mathrm{I}_{\mathrm{T} 1,65} \times \mathrm{I}_{\mathrm{T} 2,65} \\
& \mathrm{I}_{\mathrm{T} 1,80} \times \mathrm{I}_{\mathrm{T} 2,80} \\
& \mathrm{Ta}_{\mathrm{T} 1,65} \times \mathrm{Ta}_{\mathrm{T} 2,65} \\
& \mathrm{Ta}_{\mathrm{T} 1,80} \times \mathrm{Ta}_{\mathrm{T} 2,80}
\end{aligned}
$$

Pergunta (4) "existe diferença no comportamento deste componente em relação ao estado de treinamento prévio ao exercício físico?" - Comparação direta simples entre NT e T1, a $65 \%$ e $80 \%$, separadamente.

$$
\begin{aligned}
& \mathrm{I}_{\mathrm{T} 1,65} \times \mathrm{I}_{\mathrm{NT}, 65} \\
& \mathrm{I}_{\mathrm{T} 1,80} \times \mathrm{I}_{\mathrm{NT}, 80} \\
& \mathrm{Ta}_{\mathrm{T} 1,65 \times \mathrm{Ta}} \mathrm{NT}_{, 65} \\
& \mathrm{Ta}_{\mathrm{T} 1,80} \times \mathrm{Ta}_{\mathrm{NT}, 80}
\end{aligned}
$$




\section{IV - Resultados}

\section{1 - Resultados dos ajustes metodológicos em busca do estado de regime permanente no exercício físico, e dos horários mais apropriados de coletas hormonais.}

Em corridas com metas de $\mathrm{FCT}_{65}$ e $\mathrm{FCT}_{80}$, os resultados de teste piloto realizado com um indivíduo treinado e outro não treinado buscando metas de regime permanente de corrida seguem-se abaixo.

Voluntário treinado $\left(\mathrm{FCT}_{65}\right)$ :

Meta de FCT $65: 142$ bpm. Média da FC alcançada: 143 bpm. Velocidade de corrida: $10,5 \mathrm{~km} / \mathrm{h}$. Pontuação na escala de Borg e Noble (1974): 12. Ver figura 2.

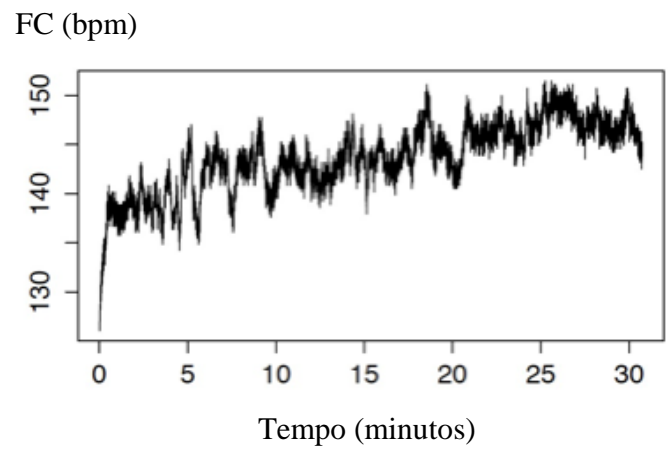

Figura 2. Frequência cardíaca ( $\mathrm{bpm}$ ) ao longo do tempo ( $\mathrm{min})$ no teste piloto de um voluntário treinado com FCT de $65 \%$. Note o aumento inicial a partir da FC de repouso e a deriva cardíaca. Apesar desta deriva, a frequência ficou próxima ao valor alvo estabelecido (ver texto). Nesta ocasião não foram necessárias alterações na velocidade de corrida para se atingir a FC alvo desejada.

\section{Voluntário treinado $\left(\mathrm{FCT}_{80}\right)$ :}

Meta de FC: 161 bpm. Média da FC alcançada: 154 bpm. Velocidade de corrida média: $12 \mathrm{~km} / \mathrm{h}$. Escala de Borg e Noble: 14. Ver figura 3. 


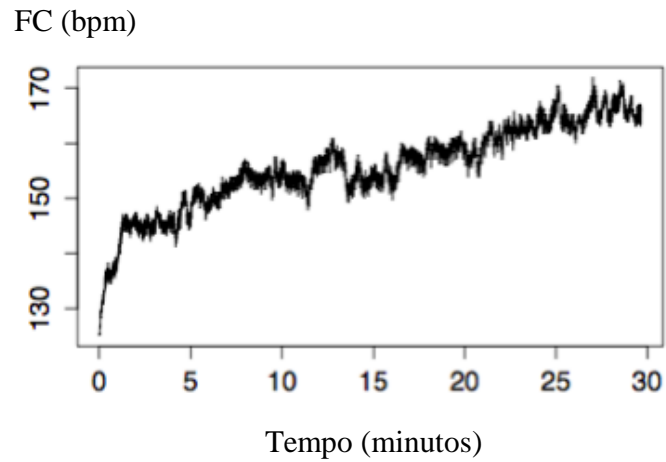

Figura 3 - Frequência cardíaca (bpm) ao longo do tempo (min) no teste piloto de um voluntário treinado com FCT de $80 \%$..

Voluntário treinado:

Razão T/C antes, logo após e cerca de três horas depois de sessão de exercício físico (corrida em esteira em $\mathrm{FCT}_{65}$ e $\mathrm{FCT}_{80}$ ). Ver figura 4.

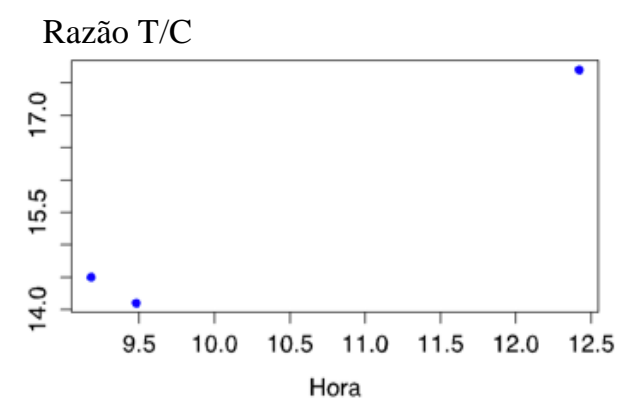

$\mathrm{FCT}_{65}$

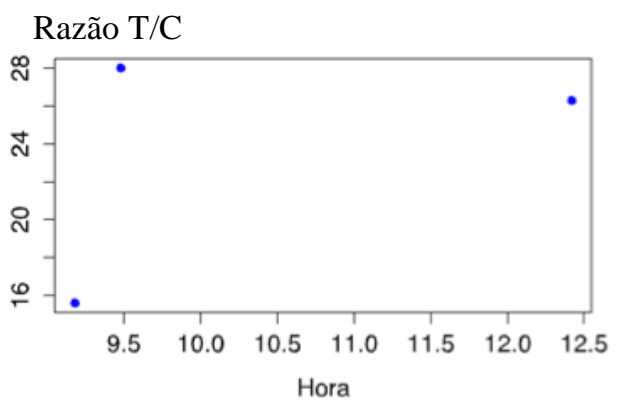

$\mathrm{FCT}_{80}$

Figura 4 - Razão T/C nas ordenadas (razão X 10-3) e horas nas abscissas em números decimais. Em corrida em $\mathrm{FCT}_{65}$ observa-se queda da razão logo após a sessão de exercício físico (9 horas e 30 minutos) e aumento da razão às 12 horas e 30 minutos (pós-teste tardio). Já em $\mathrm{FCT}_{80}$, temos um aumento da razão no pós-teste imediato e leve queda da razão no pós-teste tardio, em relação ao pósteste imediato.

Voluntário não-treinado $\left(\mathrm{FCT}_{65}\right)$ :

Meta de FC: 145 bpm. Média da FC alcançada: 155 bpm. Velocidade de corrida média: 6,6 km/h. Escala de Borg e Noble: 13. Ver figura 5. 


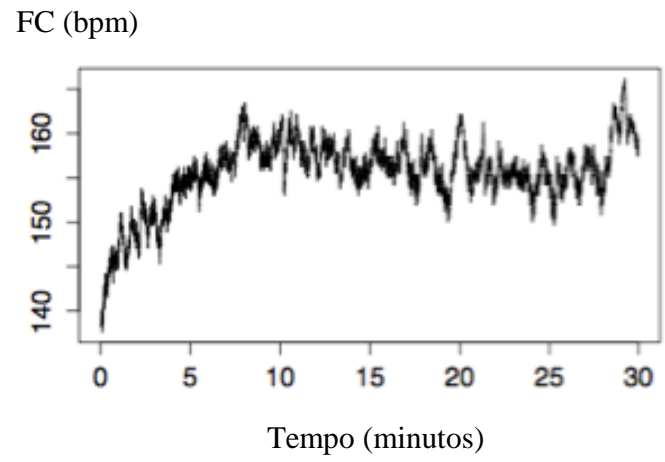

Figura 5 - Frequência cardíaca (bpm) ao longo do tempo (min) no teste piloto de um voluntário nãotreinado com FCT de $65 \%$.

Voluntário não-treinado $\left(\mathrm{FCT}_{80}\right)$ :

Meta de FC: 163 bpm. Média da FC alcançada: $171 \mathrm{bpm}$. Velocidade de corrida: 7,6 $\mathrm{km} / \mathrm{h}$. Escala de Borg e Noble: 15. Ver figura 6.

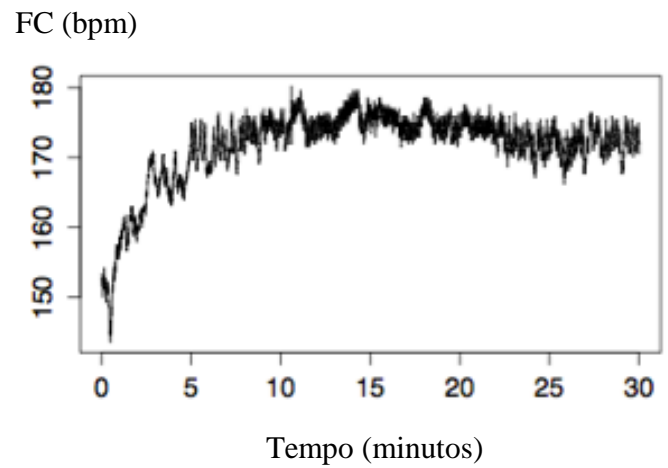

Figura 6- Frequência cardíaca (bpm) ao longo do tempo (min) no teste piloto de um voluntário nãotreinado com FCT de $80 \%$.

Voluntário não-treinado:

Na figura 7 temo razão T/C antes, logo após e cerca de três horas depois de sessão exercício físico agudo (corrida em esteira em $\mathrm{FCT}_{65}$ e $\mathrm{FCT}_{80}$ ).

Razão T/C

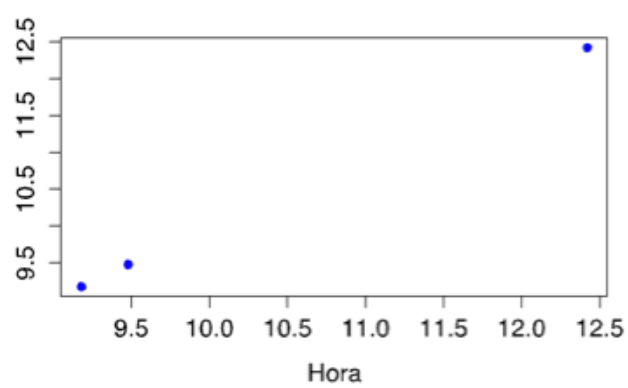

$\mathrm{FCT}_{65}$

\section{Razão T/C}

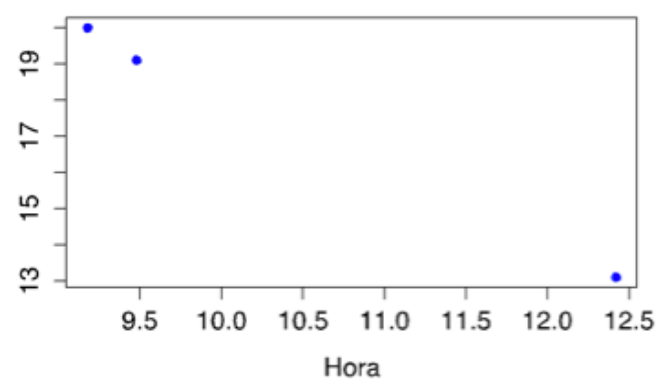

$\mathrm{FCT}_{80}$ 
Figura 7 - Razão T/C nas ordenadas (razão X 10³) e horas nas abscissas em números decimais. Em corrida em FCT $_{65}$ observa-se aumento da razão logo após a sessão de exercício físico (9 horas e 30 minutos) e aumento da razão às 12 horas e 30 minutos (pós-teste tardio). Já em $\mathrm{FCT}_{80}$, temos uma queda da razão no pós-teste imediato e uma queda maior da razão no pós-teste tardio, em relação ao pós-teste imediato.

Na figura 8 temos a razão T/C de amostras basais dos dois voluntários do teste piloto.

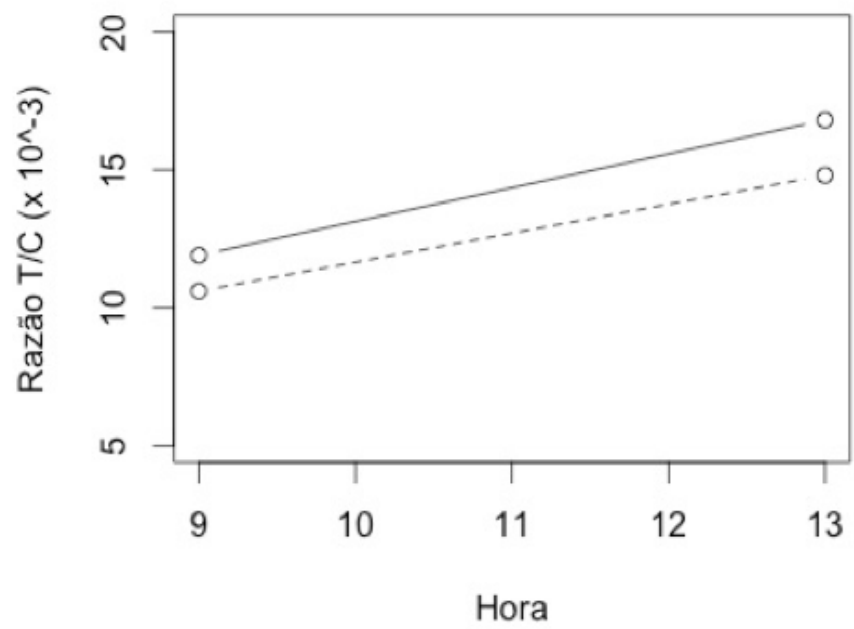

Figura 8 - Razão T/C nos horários das 09:00 e das 13:00. Voluntário não-treinado (linha tracejada) e voluntário treinado (linha contínua). É possível observar um pequeno aumento das razões basais às 13 horas em relação às 8 horas em ambos os voluntários.

\section{Conclusões do teste piloto:}

\section{Regime permanente no exercício físico}

A avaliação inicial de dois voluntários (um treinado e outro não-treinado) foi importante para se estabelecer o denominado regime permanente de corrida. Manter a FC no voluntário não-treinado dentro da meta de FCT almejada foi mais difícil do que no voluntário treinado, mesmo tendo sido feito testes iniciais de resposta de FC mediante diferentes velocidades de corrida (dia 0). Assim, foi tomada a decisão de, a cada 5 minutos, fazer pequenas alterações na velocidade de corrida caso fosse necessário. O regime permanente nesse estudo, a partir destes testes iniciais, foi considerado como uma janela de variação em torno da FC alvo de mais ou menos 10 batimentos cardíacos.

\section{Coletas hormonais}

Nestes experimentos piloto, os horários de coleta de saliva não foram pré-fixados, sendo que as amostras tardias aconteceram nos dias de corrida após às 12:00. As 
coletas basais foram realizadas às 9:00 e às 13:00. Como o cortisol após às 12:00 costuma a cair naturalmente, para se evitar tal fenômeno como interferência em nossas análises, optou-se por horários fixos de coleta (pré-teste: $8 \mathrm{~h} 00 \mathrm{~min}$; pósteste: entre $8 \mathrm{~h} 30$ e 9 h00min; e pós-teste tardio: $11 \mathrm{~h} 15 \mathrm{~min})$ para a continuidade do estudo com os 18 voluntários.

\section{2 - Resultados gerais sem tratamento estatístico}

A Tabela 1 e 2 apresenta os resultados de todas as mensurações para todos os indivíduos que participaram do presente estudo.

Tabela 1 - Resultados gerais de todos os indivíduos do estudo.

\begin{tabular}{|c|c|c|c|c|c|c|}
\hline \multirow{3}{*}{ Grupos } & \multirow[b]{3}{*}{ Indivíduos } & \multirow{3}{*}{$\begin{array}{l}\text { Gordura } \\
\text { corpórea } \\
(\%)\end{array}$} & \multicolumn{4}{|c|}{ Basal } \\
\hline & & & \multicolumn{2}{|c|}{$\mathrm{C}(\mathrm{ng} / \mathrm{ml})$} & \multicolumn{2}{|c|}{$\mathrm{T}(\mathrm{pg} / \mathrm{ml})$} \\
\hline & & & $8: 00$ & $11: 00$ & $8: 00$ & $11: 00$ \\
\hline \multirow{6}{*}{ NT } & 1 & 15 & 5,30 & 4,50 & 52,0 & 64,0 \\
\hline & 2 & 8,1 & 5,70 & 3,60 & 79,0 & 55,0 \\
\hline & 3 & 9,1 & 4,50 & 6,20 & 59,0 & 83,0 \\
\hline & 4 & 12,0 & 8,20 & 5,41 & 77,8 & 68,2 \\
\hline & 5 & 6,2 & 6,21 & 4,13 & 77,1 & 69,3 \\
\hline & 6 & 11,7 & 7,20 & 4,36 & 62,5 & 58,5 \\
\hline \multirow{7}{*}{$\mathrm{T} 1$} & & & & & & \\
\hline & 1 & 13,4 & 6,10 & 6,30 & 53,0 & 61,0 \\
\hline & 2 & 11,2 & 6,50 & 3,20 & 72,0 & 78,0 \\
\hline & 3 & 8,4 & 5,10 & 6,50 & 59,0 & 63,0 \\
\hline & 4 & 15,3 & 6,42 & 4,32 & 77,9 & 43,0 \\
\hline & 5 & 15,3 & 8,43 & 5,30 & 83,5 & 79,5 \\
\hline & 6 & 13,6 & 9,40 & 4,81 & 67,7 & 61,5 \\
\hline \multirow{6}{*}{$\mathrm{T} 2$} & 1 & 14,9 & 8,30 & 4,77 & 74,1 & 71,8 \\
\hline & 2 & 18,3 & 5,21 & 4,62 & 67,0 & 57,7 \\
\hline & 3 & 10,5 & 7,33 & 4,90 & 89.5 & 46,2 \\
\hline & 4 & 9,8 & 9,40 & 5,8 & 95,2 & 92,3 \\
\hline & 5 & 13,4 & 7,80 & 4,32 & 92,1 & 89,2 \\
\hline & 6 & 15 & 10,20 & 6,30 & 77,2 & 71,5 \\
\hline
\end{tabular}

$\mathrm{NT}=$ não-treinados. $\mathrm{T} 1$ e $\mathrm{T} 2=$ treinados. $\mathrm{C}=$ cortisol $(\mathrm{ng} / \mathrm{ml}) . \mathrm{T}=$ testosterona $(\mathrm{pg} / \mathrm{ml}) . \%$ de gordura corporal: estimativa da porcentagem de gordura corpórea segundo método de Jackson e Pollok (1978) utilizando 7 pregas cutâneas. Basal: dosagens de cortisol e testosterona às 8 horas e às 11 horas em dias em que não se praticou exercício físico. 
Tabela 2 - Resultados gerais de todos os indivíduos do estudo.

\begin{tabular}{|c|c|c|c|c|c|c|c|c|c|c|c|c|}
\hline \multirow{3}{*}{ Grupos } & \multirow[b]{3}{*}{ Indivíduo } & \multicolumn{11}{|c|}{$65 \%$} \\
\hline & & \multicolumn{3}{|c|}{$\mathrm{C}(\mathrm{ng} / \mathrm{ml})$} & \multicolumn{3}{|c|}{$\mathrm{T}(\mathrm{pg} / \mathrm{ml})$} & \multicolumn{2}{|c|}{ Glicemia (mg/dl) } & \multirow{2}{*}{$\begin{array}{c}\text { FC média } \\
(\mathrm{bpm})\end{array}$} & \multirow{2}{*}{$\begin{array}{c}\text { Tempo de } \\
\text { corrida } \\
\text { (min) }\end{array}$} & \multirow{2}{*}{$\begin{array}{l}\text { Batimentos } \\
\text { totais }\end{array}$} \\
\hline & & pré & pós & tardio & pré & pós & tardio & antes & depois & & & \\
\hline \multirow{6}{*}{ NT } & 1 & 5,00 & 3,00 & 4,40 & 57,0 & 53,0 & 59,0 & 120 & 93 & 150 & 30 & 4500 \\
\hline & 2 & 4,10 & 4,00 & 3,90 & 62,0 & 59,0 & 53,0 & 74 & 88 & 159 & 30 & 4770 \\
\hline & 3 & 4,20 & 5,70 & 3,10 & 72,0 & 69,0 & 58,0 & 89 & 93 & 145 & 30 & 4350 \\
\hline & 4 & 7,22 & 5,11 & 5,76 & 84,6 & 79,7 & 68,4 & 91 & 90 & 154 & 30 & 4620 \\
\hline & 5 & 4,12 & 3,79 & 2,99 & 85,7 & 73,2 & 67,5 & 107 & 85 & 140 & 30 & 4200 \\
\hline & 6 & 7,31 & 5,23 & 4,12 & 67,2 & 64,1 & 65,3 & 81 & 90 & 155 & 30 & 4650 \\
\hline & & & & & & & & & & & & \\
\hline \multirow{6}{*}{$\mathrm{T} 1$} & 1 & 6,40 & 3,70 & 5,80 & 67,0 & 58,0 & 53,0 & 100 & 91 & 146 & 30 & 4380 \\
\hline & 2 & 3,70 & 4,90 & 3,80 & 72,0 & 58,0 & 56,0 & 94 & 111 & 139 & 30 & 4170 \\
\hline & 3 & 4,50 & 3,10 & 4,00 & 67,0 & 56,0 & 52,0 & 85 & 80 & 133 & 30 & 3990 \\
\hline & 4 & 4,21 & 3,67 & 3,00 & 71,4 & 65,2 & 51,7 & 101 & 99 & 128 & 30 & 3840 \\
\hline & 5 & 4,80 & 3,70 & 3,30 & 76,4 & 74,2 & 73,9 & 96 & 117 & 123 & 30 & 3690 \\
\hline & 6 & 5,22 & 4,37 & 4,00 & 64,2 & 61,3 & 60,6 & 102 & 76 & 135 & 30 & 4050 \\
\hline \multirow{6}{*}{$\mathrm{T} 2$} & 1 & 751 & 467 & 409 & 683 & $62 ?$ & 617 & 87 & 88 & 140 & 45 & 6300 \\
\hline & 2 & 6,32 & 5,11 & 3,88 & 69,0 & 57,3 & 56,2 & 105 & 108 & 128 & 49 & 6300 \\
\hline & 3 & 6,42 & 4,21 & 3,12 & 59,8 & 72,4 & 51,8 & 100 & 116 & 146 & 43 & 6300 \\
\hline & 4 & 4,56 & 3,94 & 3,25 & 90,1 & 87,1 & 86,2 & 88 & 101 & 119 & 53 & 6300 \\
\hline & 5 & 7,37 & 5,19 & 3,25 & 71,3 & 69,4 & 59,9 & 100 & 103 & 140 & 45 & 6300 \\
\hline & 6 & 6,47 & 4,97 & 3,80 & 82,9 & 73,8 & 62,6 & 101 & 99 & 150 & 42 & 6300 \\
\hline
\end{tabular}

\begin{tabular}{|c|c|c|c|c|c|c|c|c|c|c|c|c|}
\hline \multirow{3}{*}{ Grupos } & \multirow[b]{3}{*}{ Indivíduo } & \multicolumn{11}{|c|}{$80 \%$} \\
\hline & & \multicolumn{3}{|c|}{$\mathrm{C}(\mathrm{ng} / \mathrm{ml})$} & \multicolumn{3}{|c|}{$\mathrm{T}(\mathrm{pg} / \mathrm{ml})$} & \multicolumn{2}{|c|}{ Glicemia (mg/dl) } & \multirow{2}{*}{$\begin{array}{c}\text { FC média } \\
(\mathrm{bpm})\end{array}$} & \multirow{2}{*}{$\begin{array}{c}\text { Tempo de } \\
\text { corrida } \\
\text { (min) }\end{array}$} & \multirow{2}{*}{$\begin{array}{c}\text { Batimentos } \\
\text { totais }\end{array}$} \\
\hline & & pré & pós & tardio & pré & pós & tardio & antes & depois & & & \\
\hline \multirow{6}{*}{ NT } & 1 & 5,30 & 4,10 & 2,60 & 72,0 & 54,0 & 66,0 & 101 & 83 & 164 & 30 & 4920 \\
\hline & 2 & 6,20 & 3,90 & 4,20 & 60,0 & 54,0 & 62,0 & 98 & 78 & 169 & 30 & 5070 \\
\hline & 3 & 4,00 & 6,60 & 3,20 & 53,0 & 56,0 & 72,0 & 126 & 89 & 161 & 30 & 4830 \\
\hline & 4 & 4,92 & 3,77 & 5,10 & 93,2 & 89,1 & 77,3 & 96 & 95 & 163 & 30 & 4890 \\
\hline & 5 & 3,45 & 2,86 & 2,47 & 58,2 & 67,1 & 58,4 & 103 & 90 & 153 & 30 & 4590 \\
\hline & 6 & 4,68 & 3,72 & 4,72 & 98,3 & 79,4 & 67,3 & 88 & 93 & 160 & 30 & 4800 \\
\hline \multirow{6}{*}{$\mathrm{T} 1$} & 1 & 4,80 & 4,90 & 5,60 & 62,0 & 72,0 & 56,0 & 84 & 107 & 157 & 30 & 4710 \\
\hline & 2 & 4,90 & 3,80 & 3,70 & 50,0 & 66,0 & 64,0 & 101 & 93 & 156 & 30 & 4680 \\
\hline & 3 & 4,80 & 3,10 & 3,70 & 63,0 & 51,0 & 50,0 & 84 & 89 & 151 & 30 & 4530 \\
\hline & 4 & 5,31 & 4,99 & 3,56 & 59,8 & 78,2 & 56,3 & 97 & 90 & 141 & 30 & 4230 \\
\hline & 5 & 6,30 & 5,20 & 4,70 & 84,1 & 79,4 & 85,2 & 93 & 128 & 141 & 30 & 4230 \\
\hline & 6 & 7,68 & 4,76 & 4,55 & 100,2 & 79,1 & 68,4 & 123 & 108 & 156 & 30 & 4680 \\
\hline \multirow{6}{*}{$\mathrm{T} 2$} & 1 & 4.29 & 362 & 4.97 & 918 & 841 & 787 & 84 & 115 & 161 & 39 & 6300 \\
\hline & 2 & 398 & 273 & 261 & $61 ?$ & 734 & $55 ?$ & 89 & 133 & 140 & 45 & 6300 \\
\hline & 3 & 5,11 & 3,09 & 2,14 & 68,3 & 72,4 & 51,5 & 89 & 120 & 157 & 40 & 6300 \\
\hline & 4 & 3,98 & 2,93 & 2,72 & 70,2 & 67,7 & 64,1 & 94 & 101 & 131 & 48 & 6300 \\
\hline & 5 & 3,65 & 2,88 & 2,56 & 67,4 & 63,8 & 59,7 & 94 & 98 & 150 & 42 & 6300 \\
\hline & 6 & 5,00 & 3,21 & 4,62 & 89,4 & 76,3 & 72,5 & 97 & 98 & 158 & 40 & 6300 \\
\hline
\end{tabular}

$\mathrm{NT}=$ não-treinados. $\mathrm{T} 1$ e T2 $=$ treinados. $\mathrm{C}=\operatorname{cortisol}(\mathrm{ng} / \mathrm{ml}) . \mathrm{T}=$ testosterona $(\mathrm{pg} / \mathrm{ml})$. Glicemia capilar $(\mathrm{mg} / \mathrm{dL}) .65 \%$ e $80 \%$ = percentual da potência do exercício físico na fórmula de Karvonen (1957). Glicemia: glicemia capilar antes e depois das corridas. Batimentos totais: batimentos cardíacos totais. FC: frequiência cardíaca (batimentos por minutos). 
A tabela 3 apresenta os resultados da razão T/C para todos os indivíduos em todos os horários.

Tabela 3 - Razões T/C (basais e em corridas em $\mathrm{FCT}_{65}$ e $\mathrm{FCT}_{80}$ )

\begin{tabular}{|c|c|c|c|c|c|c|c|c|c|}
\hline \multirow{3}{*}{ Grupos } & & Basal & & \multicolumn{3}{|c|}{$65 \%$} & \multicolumn{3}{|c|}{$80 \%$} \\
\hline & & \multicolumn{2}{|c|}{$\mathrm{T} / \mathrm{C}$} & \multicolumn{3}{|c|}{$\mathrm{T} / \mathrm{C}$} & \multicolumn{3}{|c|}{$\mathrm{T} / \mathrm{C}$} \\
\hline & Indivíduo & $8: 00$ & $11: 00$ & pré & pós & tardio & pré & pós & tardio \\
\hline \multirow{6}{*}{ NT } & 1 & 9,8 & 14,2 & 11,4 & 17,6 & 13,4 & 13,5 & 13,1 & 25,3 \\
\hline & 2 & 13,8 & 15,2 & 15,1 & 14,7 & 13,5 & 9,6 & 13,8 & 14,7 \\
\hline & 3 & 13,1 & 13,3 & 17,1 & 12,1 & 18,7 & 13,2 & 8,4 & 22,5 \\
\hline & 4 & 9,4 & 12,6 & 11,7 & 15,6 & 11,8 & 18,9 & 23,6 & 15,1 \\
\hline & 5 & 12,4 & 16,7 & 20,8 & 19,3 & 22,5 & 16,8 & 23,4 & 23,6 \\
\hline & 6 & 8,6 & 13,4 & 9,1 & 12,2 & 15,8 & 21,0 & 21,3 & 14,2 \\
\hline & & & & & & & & & \\
\hline \multirow{6}{*}{$\mathrm{T} 1$} & 1 & 8,6 & 9,6 & 10,4 & 15,6 & 9,1 & 12,9 & 14,6 & 10,0 \\
\hline & 2 & 11,0 & 24,3 & 19,4 & 11,8 & 14,7 & 10,2 & 17,3 & 17,2 \\
\hline & 3 & 11,5 & 9,6 & 14,8 & 18,0 & 13,0 & 13,1 & 16,4 & 13,5 \\
\hline & 4 & 12,1 & 9,9 & 16,9 & 17,7 & 17,2 & 11,2 & 15,6 & 15,8 \\
\hline & 5 & 9,9 & 15 & 15,9 & 20,0 & 22,3 & 13,3 & 15,2 & 18,1 \\
\hline & 6 & 7,2 & 12,7 & 12,2 & 14,0 & 15,1 & 13,0 & 16,6 & 15,0 \\
\hline & & & & & & & & & \\
\hline \multirow{6}{*}{$\mathrm{T} 2$} & 1 & 8,9 & 15,0 & 9,0 & 13,3 & 12,3 & 21,3 & 23,2 & 15,8 \\
\hline & 2 & 12,8 & 12,4 & 10,9 & 11,2 & 14,4 & 15,3 & 26,8 & 21,1 \\
\hline & 3 & 12,2 & 9,4 & 9,3 & 17,1 & 16,6 & 13,3 & 23,4 & 24,0 \\
\hline & 4 & 10,1 & 15,9 & 19,7 & 22,1 & 26,5 & 17,6 & 23,1 & 23,5 \\
\hline & 5 & 11,8 & 20,6 & 9,6 & 13,3 & 18,4 & 18,4 & 22,1 & 23,3 \\
\hline & 6 & 7,5 & 11,3 & 12,8 & 14,8 & 16,4 & 17,8 & 23,7 & 15,6 \\
\hline
\end{tabular}

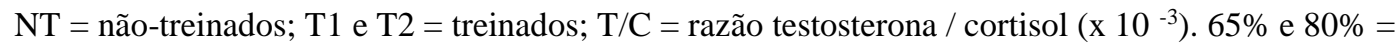
percentual da potência do exercício físico na fórmula de Karvonen (1957).

Nas figuras 9, 10, 11, 12, 13 e 14 temos os gráficos das razões T/C às 08:00 (correspondente ao pré-teste), às 09:00 (correspondente ao pós-teste imediato), às 11:00 (basal) e às 11:30 (correspondente ao pós-teste tardio). As amostras correspondentes às 09:00 e às 11:30 não foram coletadas exatamente nesse horário, mas foram dispostas assim nos gráficos por motivo de melhor visualização dos resultados. Cada ícone representa um voluntário. 


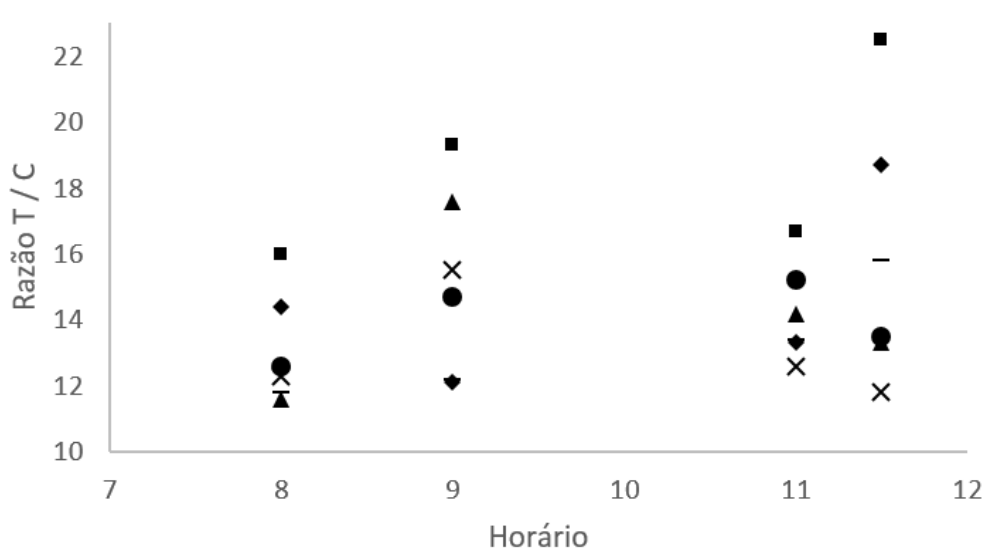

Figura 9 - Não-treinados (NT): Corridas em FCT 65. Razão T/C (x 10³) e horário.

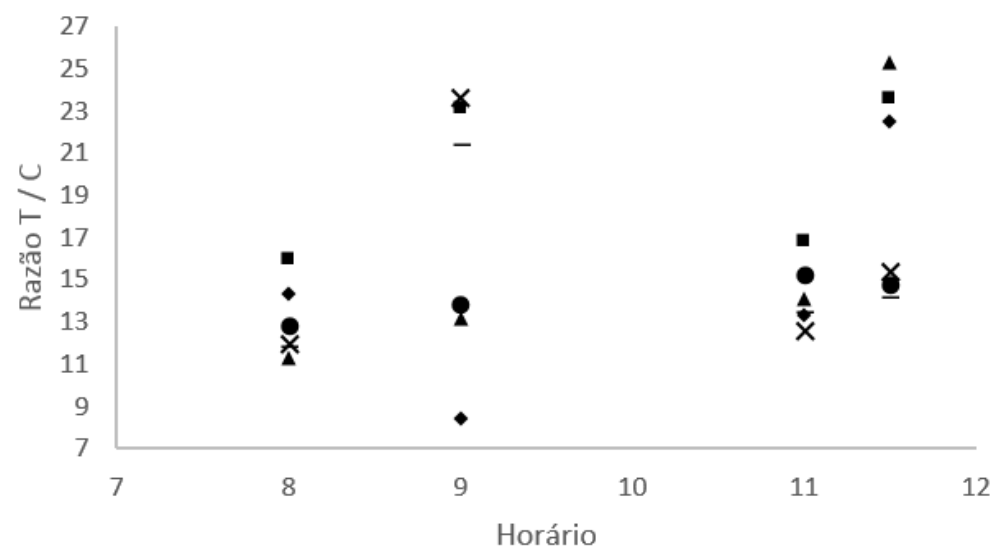

Figura 10 - Não-treinados (NT): corridas em FCT 80. Razão T/C (x 10³) e horário.

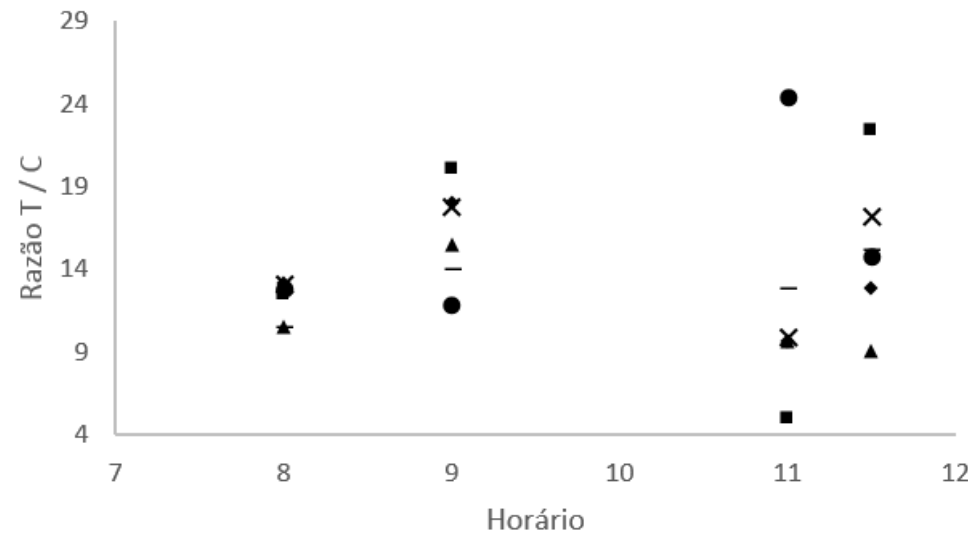

Figura 11 - Treinados (T1): corridas em $\mathrm{FCT}_{65}$. Razão T/C (x 10-3). Corridas em FCT 65 . Razão T/C (x $10^{-3}$ ) e horário. 


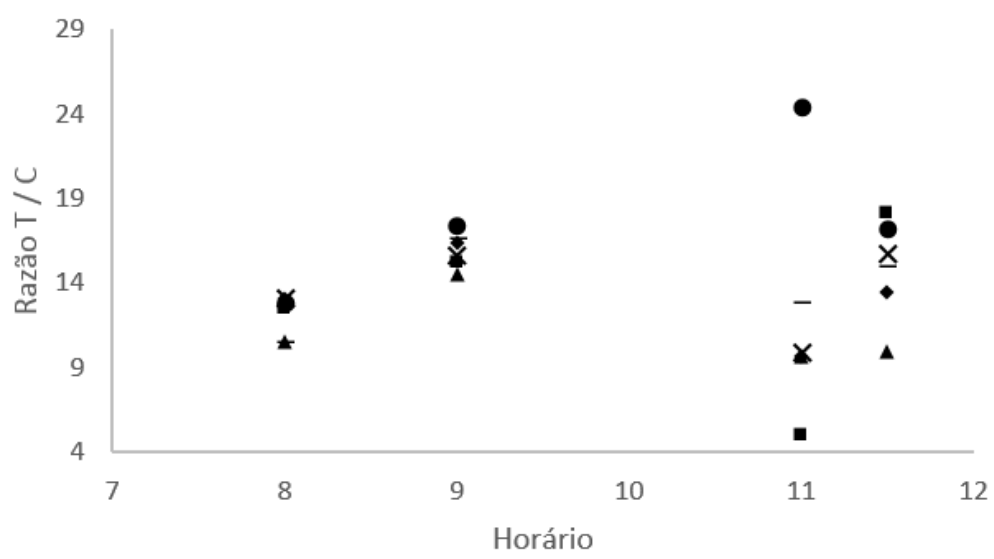

Figura 12 - Treinados (T1): corridas em FCT ${ }_{80}$. Razão T/C (x 10-3). Corridas em FCT 80. Razão T/C (x $10^{-3}$ ) e horário.

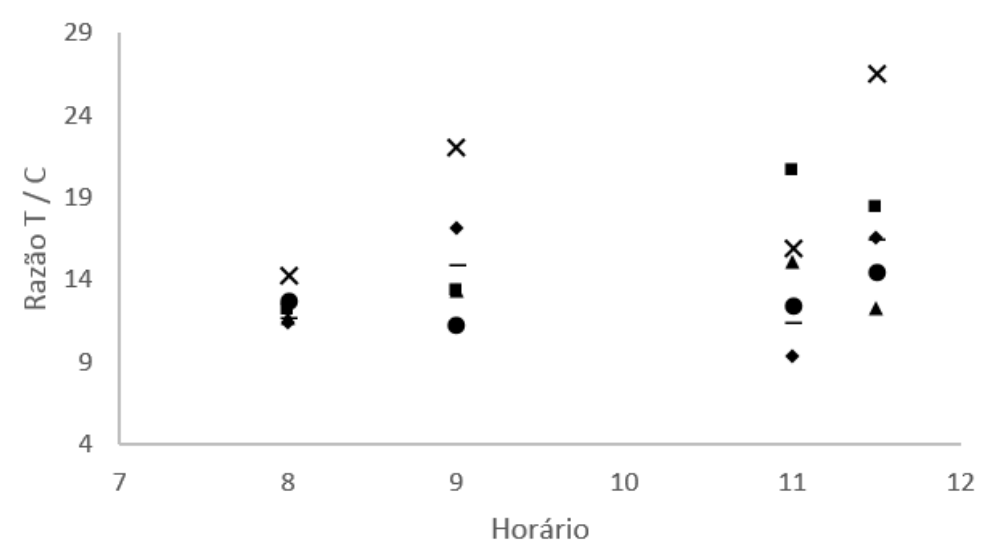

Figura 13 - Treinados (T2): corridas em FCT ${ }_{65}$. Razão T/C (x 10³). Corridas em FCT 65 . Razão T/C (x $10^{-3}$ ) e horário.

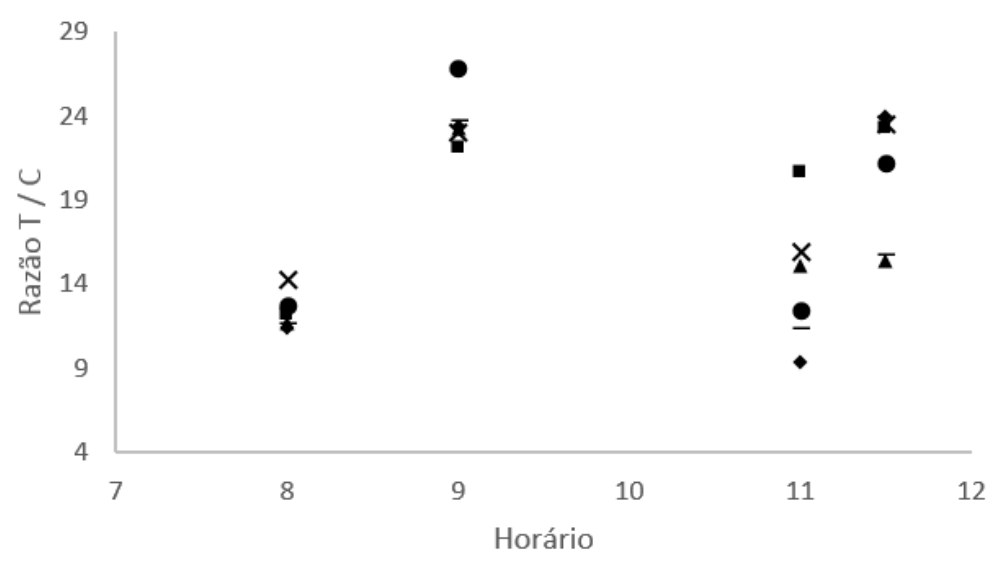

Figura 14 - Treinados (T2): corridas em FCT 80 . Razão T/C (x 10-3). Corridas em FCT 80. Razão T/C (x $\left.10^{-3}\right)$ e horário. 
Nas figuras 15, 16, 17, 18, 19 e 20, temos o cortisol às 08:00 (correspondente ao préteste), às 09:00 (correspondente ao pós-teste imediato), às 11:00 (basal) e às 11:30 (correspondente ao pós-teste tardio). As amostras correspondentes às 09:00 e às 11:30 não foram coletadas exatamente nesse horário, mas foram dispostas assim nos gráficos por motivo de melhor visualização dos resultados. Cada ícone representa um voluntário.

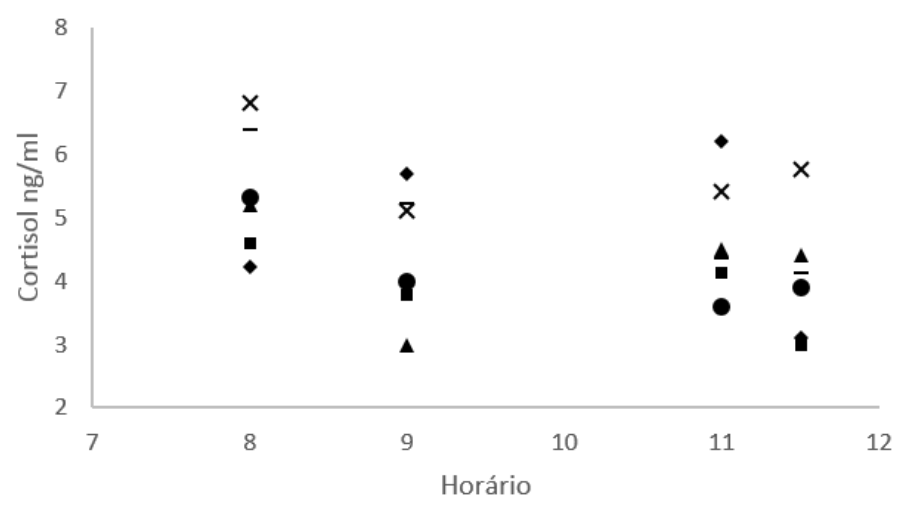

Figura 15 - Não-treinados (NT): corrida em FCT 65 (Cortisol em ng/ml e horário).

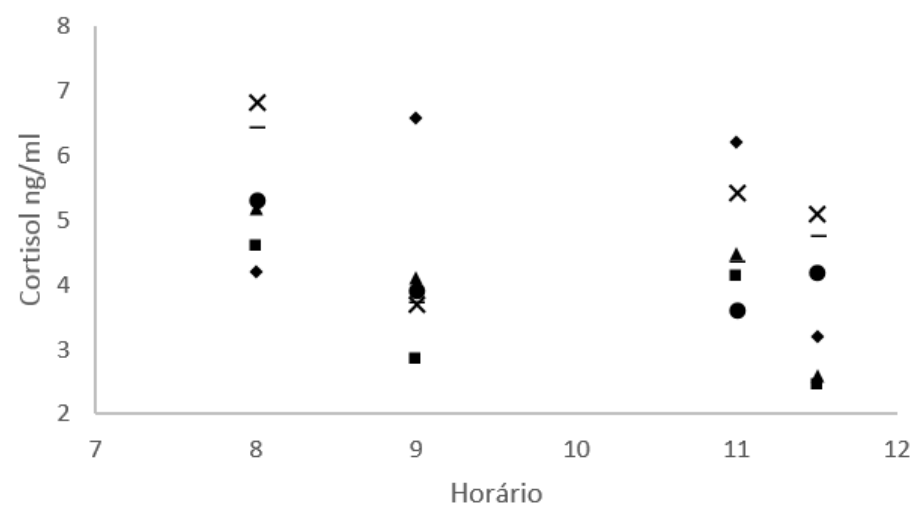

Figura 16 - Não-treinados (NT): corrida em $\mathrm{FCT}_{80}$ (Cortisol em ng/ml e horário). 


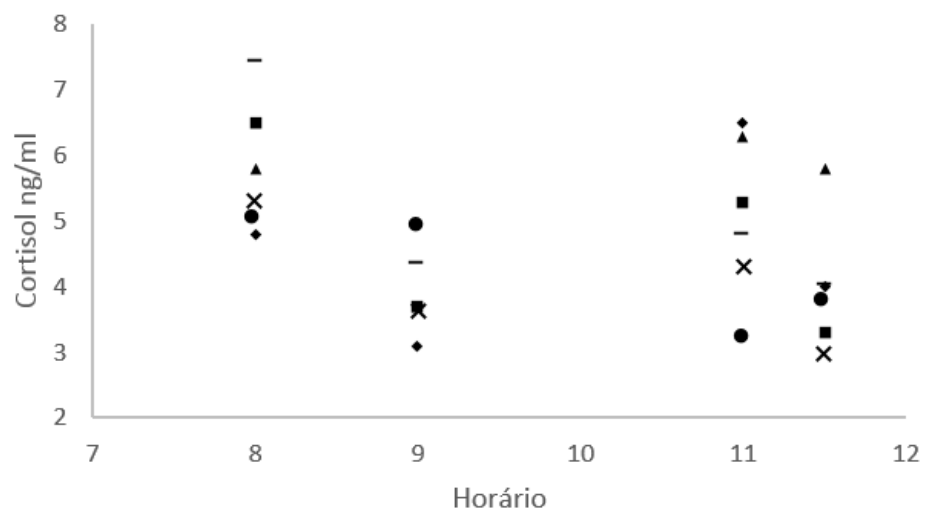

Figura 17 - Treinados (T1): corridas em $\mathrm{FCT}_{65}$ (Cortisol em ng/ml e horário).

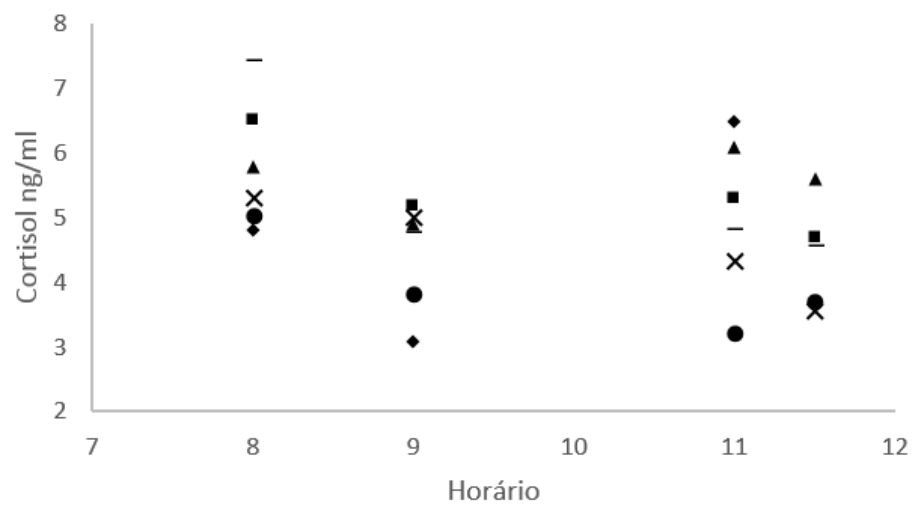

Figura 18 - Treinados (T1): corridas em $\mathrm{FCT}_{80}$ (Cortisol em ng/ml e horário).

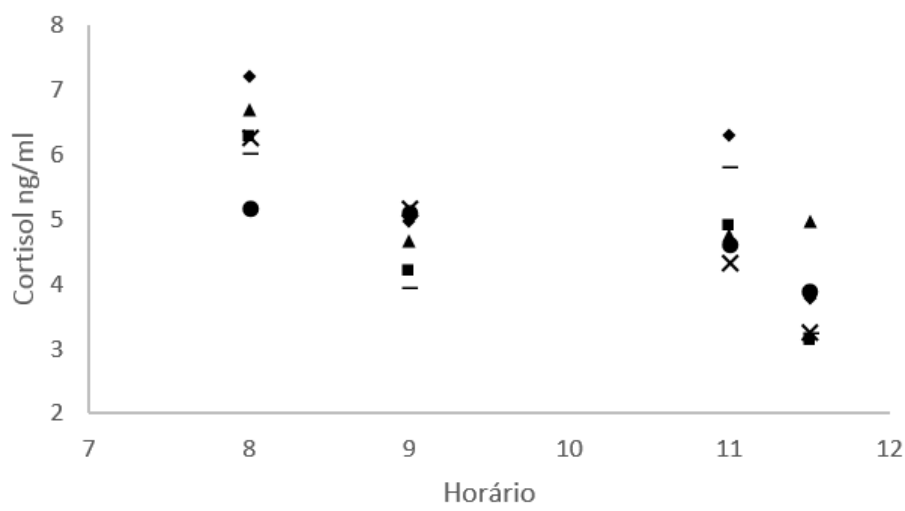

Figura 19 - Treinados (T2): corridas em $\mathrm{FCT}_{65}$ (Cortisol em ng/ml e horário). 


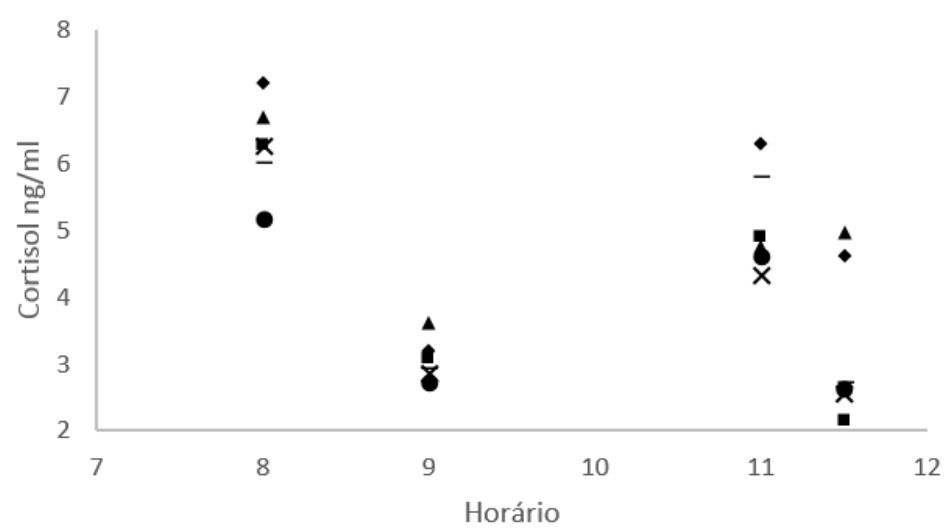

Figura 20 - Treinados (T2): corridas em $\mathrm{FCT}_{80}$ (Cortisol em ng/ml e horário).

Nas figuras 21, 22, 23, 24, 25 e 26 temos a testosterona às 08:00 (correspondente ao pré-teste), às 09:00 (correspondente ao pós-teste imediato), às 11:00 (basal) e às 11:30 (correspondente ao pós-teste tardio). As amostras correspondentes às 09:00 e às 11:30 não foram coletadas exatamente nesse horário, mas foram dispostas assim nos gráficos por motivo de melhor visualização dos resultados. Cada ícone representa um voluntário.

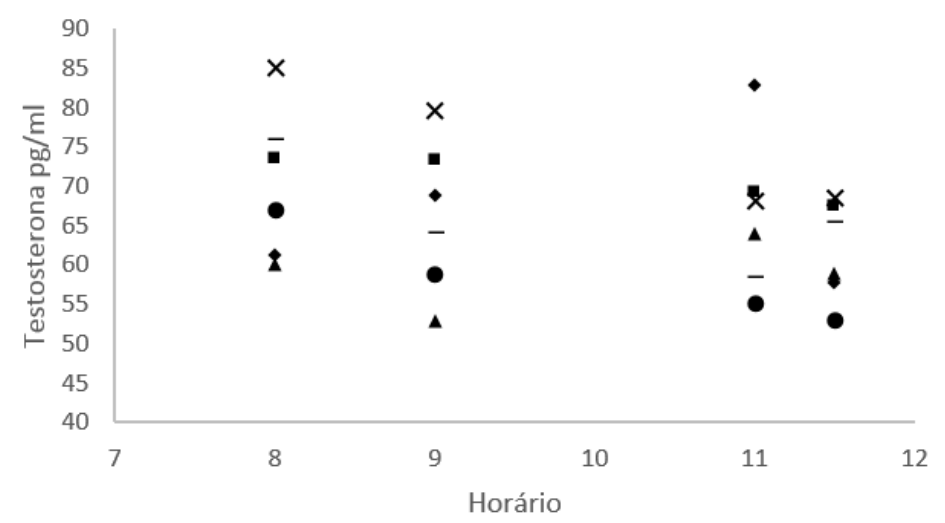

Figura 21 - Não-treinados (NT): corrida em $\mathrm{FCT}_{65}$ (testosterona em pg/ml e horário). 


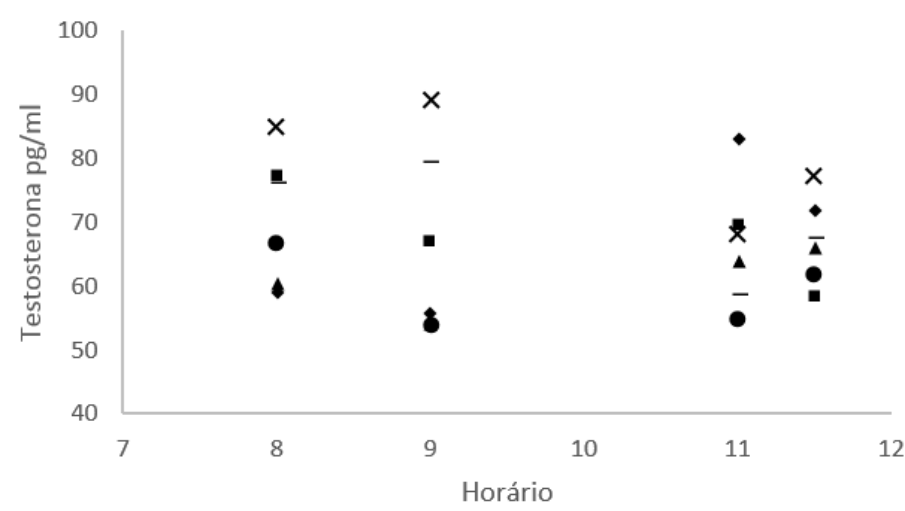

Figura 22 - Não-treinados (NT): corridas em $\mathrm{FCT}_{80}$ (testosterona em pg/ml e horário).

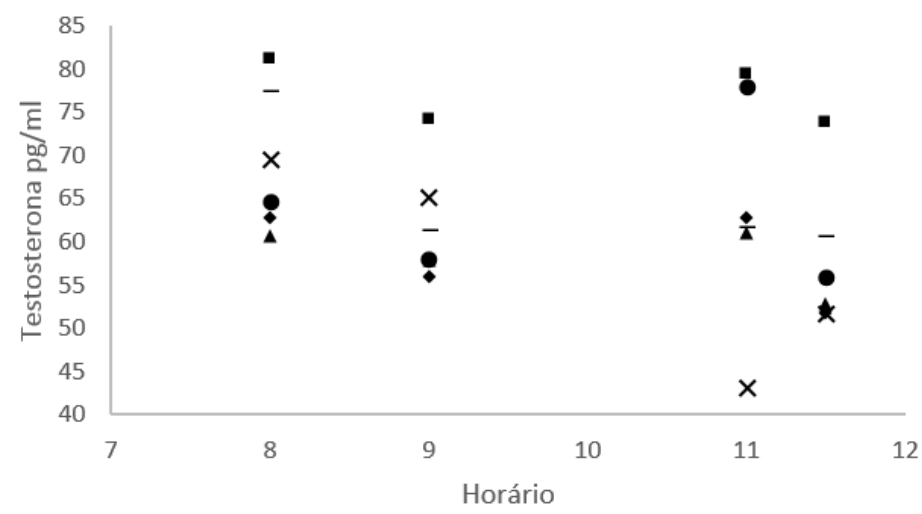

Figura 23 - Treinados (T1): corridas em $\mathrm{FCT}_{65}$ (testosterona em pg/ml e horário).

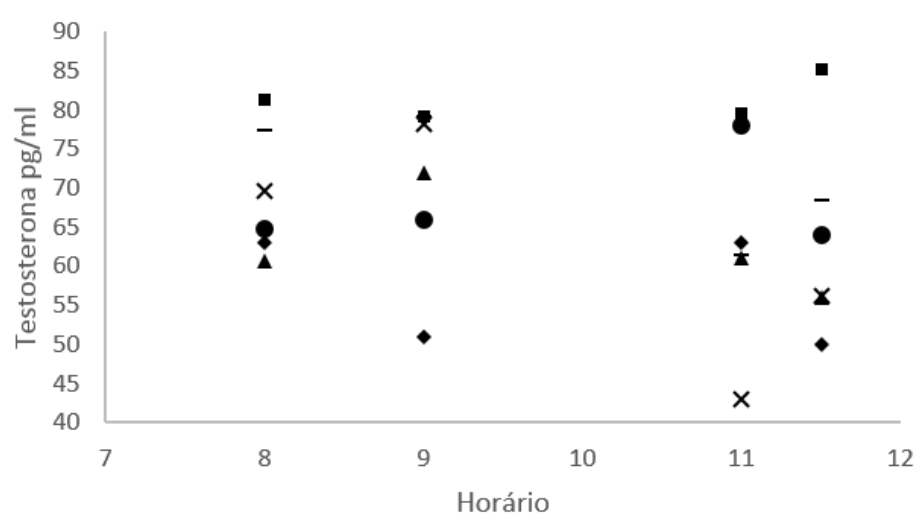

Figura 24 - Treinados (T1): corridas em $\mathrm{FCT}_{80}$ (testosterona em pg/ml e horário). 


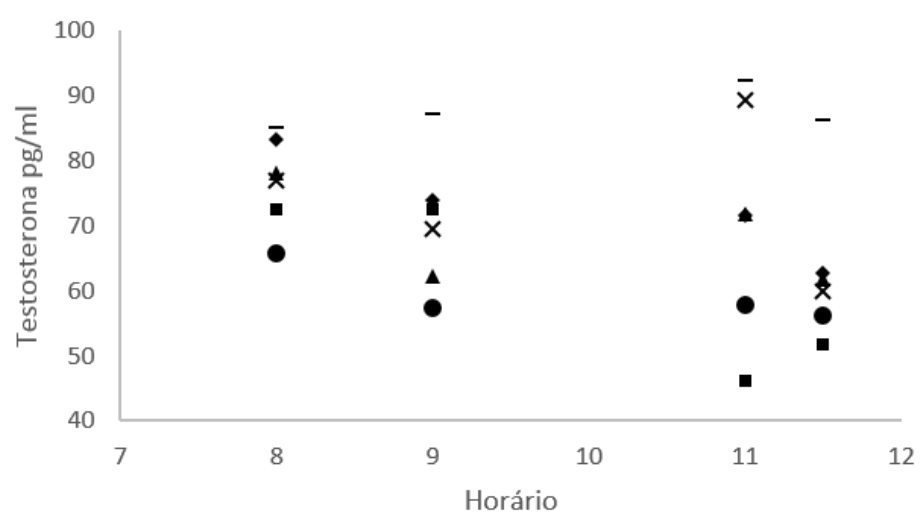

Figura 25 - Treinados (T2): corridas em $\mathrm{FCT}_{65}$ (testosterona em pg/ml e horário).

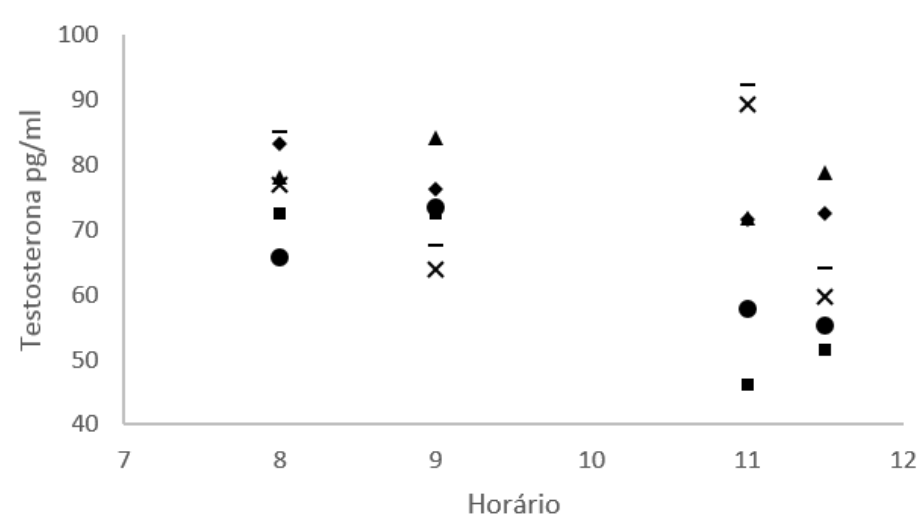

Figura 26 - Treinados (T2): corridas em $\mathrm{FCT}_{80}$ (testosterona em pg/ml e horário).

Nas figuras 27, 28 e 29, temos o cortisol, a testosterona e a razão T/C (basais) das 08:00 e das 11:00 da manhã de todos os voluntários (representados como círculos em diferentes tons de cinza). 


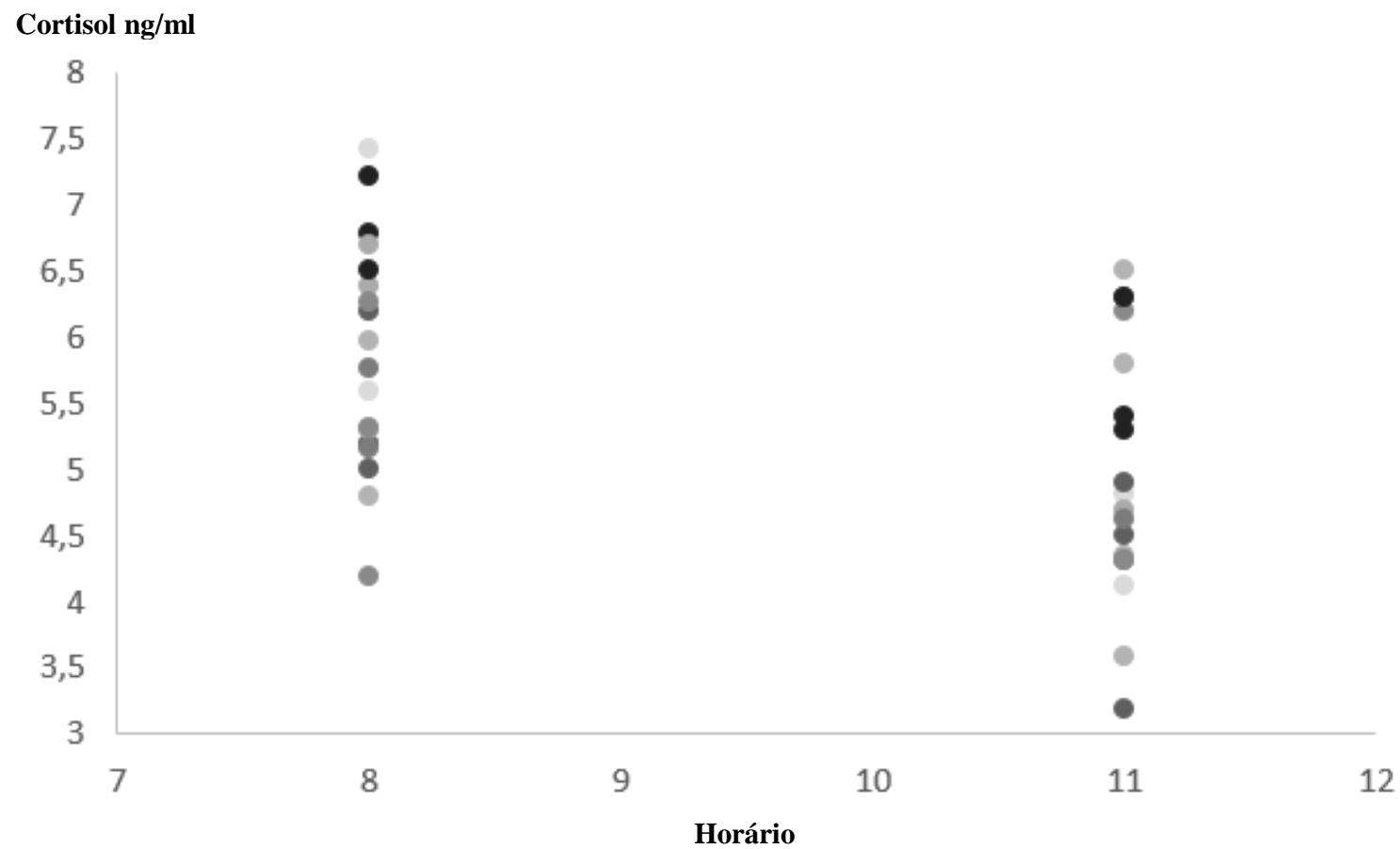

Figura 27 - Cortisol basal das 08:00 e das 11:00 (todos os voluntários). Cortisol (ng/ml) nas ordenadas e horário nas abscissas. Os indivíduos foram representados como círculos em diferentes tons de cinza.

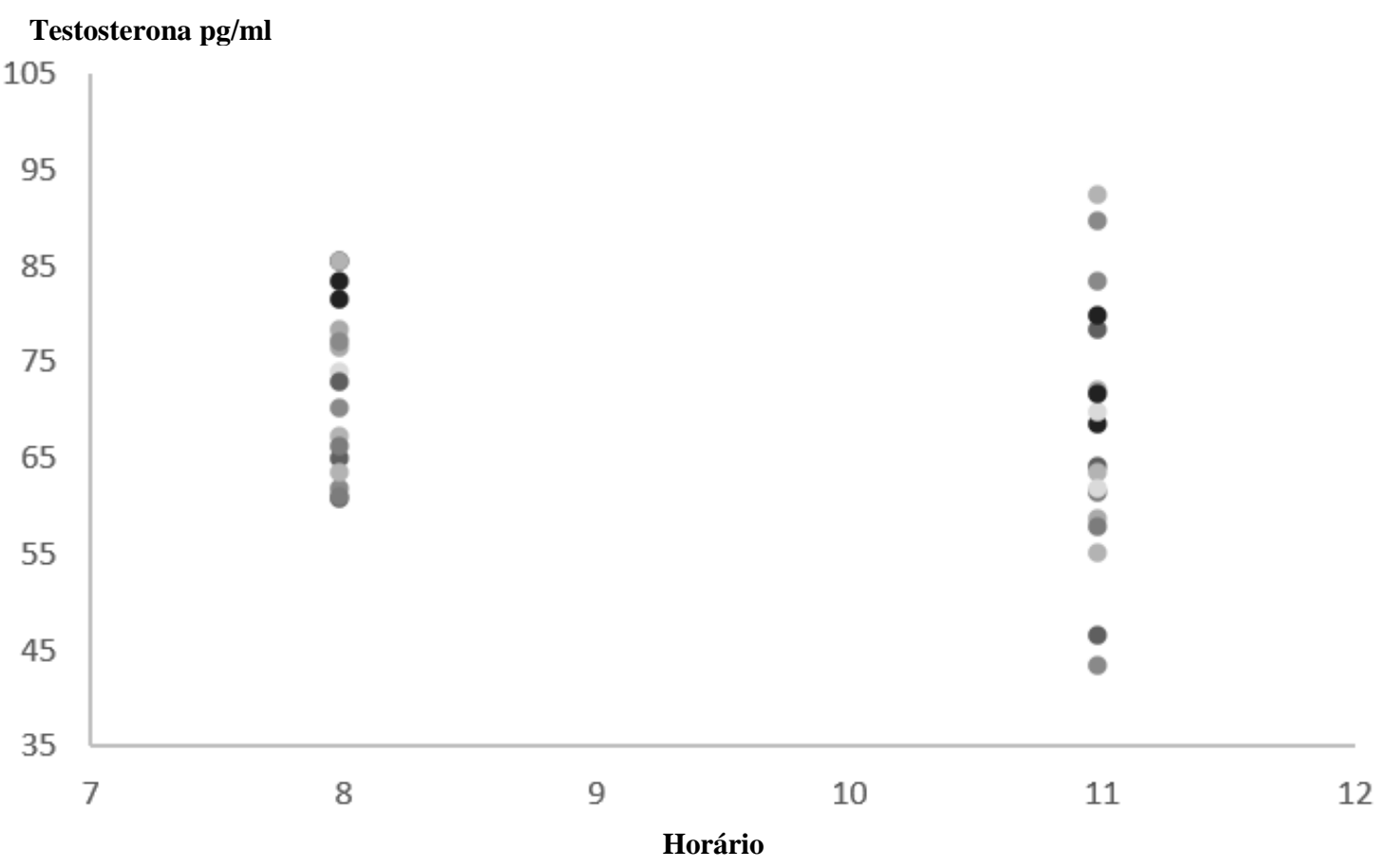

Figura 28 - Testosterona basal das 08:00 e das 11:00 (todos os voluntários). Testosterona (pg/ml) nas ordenadas e horário nas abscissas. Os indivíduos foram representados como círculos em diferentes tons de cinza. 


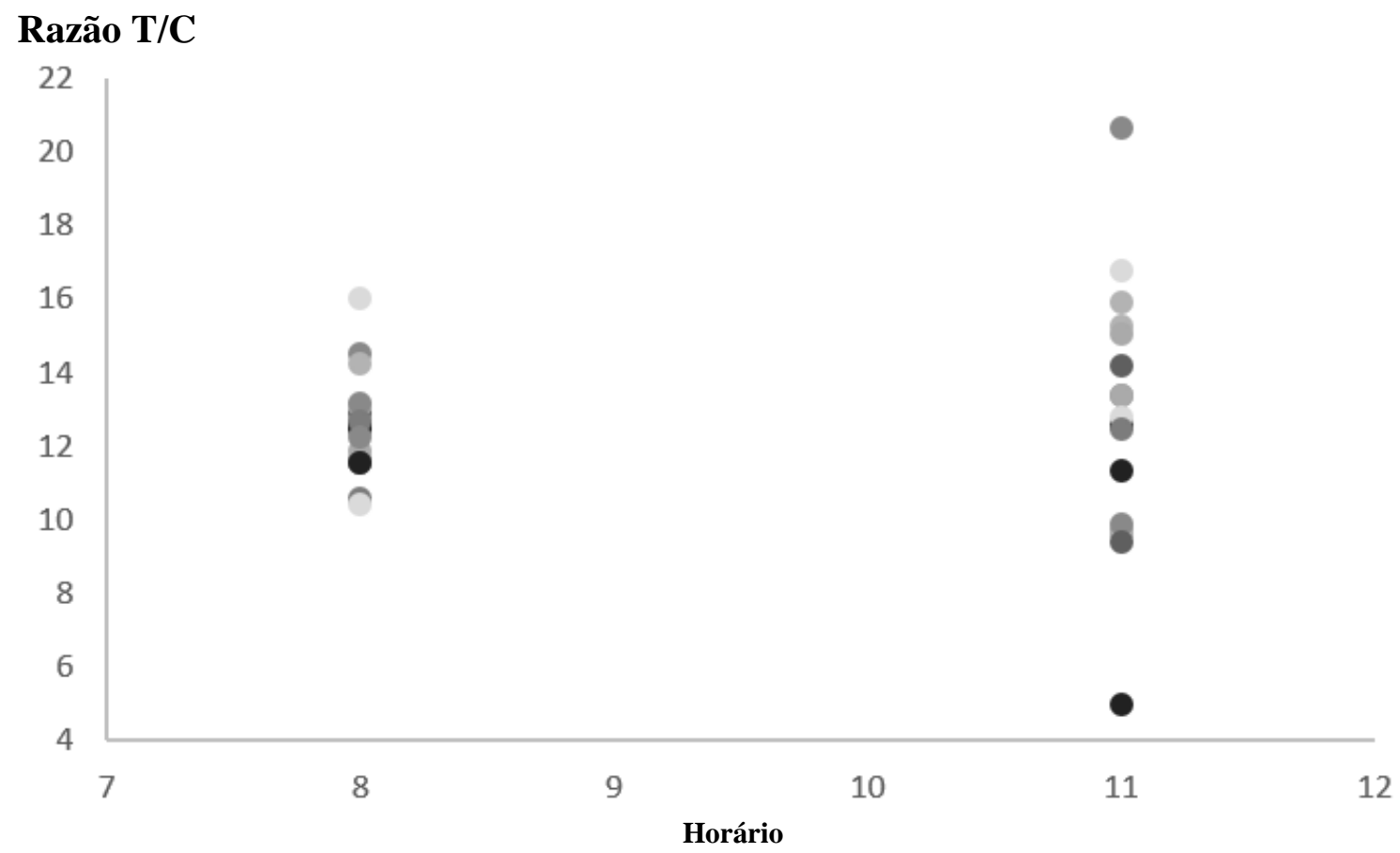

Figura 29- Razão T/C basal de todos os voluntários às 08:00 e às 11:00 da manhã. Razão T/C (x 10 $0^{-3}$ ) nas ordenadas e horário nas abscissas. Os indivíduos foram representados como círculos em diferentes tons de cinza.

\section{Nível de treinamento físico}

Os voluntários treinados correram em média na semana anterior ao experimento 42 Km ( \pm 19,2 Km). Os não-treinados tiveram atividades físicas variadas (musculação, natação, corrida e caminhada) sendo que não foi possível computar a quilometragem de corrida na última semana pelos dados informados no questionário.

\section{Ambiente laboratorial}

Os experimentos foram realizados em temperatura controlada de 21 graus Celsius $( \pm$ 0,5 graus Celsius). A umidade relativa do ar média foi de $66 \%$ ( $\pm 10 \%)$. Altitude estimada em que se encontra o laboratório: 785 metros acima do nível do mar.

\section{3 - Análises}

A tabela 4 apresenta, graficamente, os resultados individuais em termos de aumento/diminuição/não-alteração para cada um dos hormônios em cada um dos protocolos experimentais. Tais resultados foram obtidos a partir da construção dos intervalos de confiança como descritos em 3.8.1. 
Tabela 4 - Resultados: cortisol e testosterona

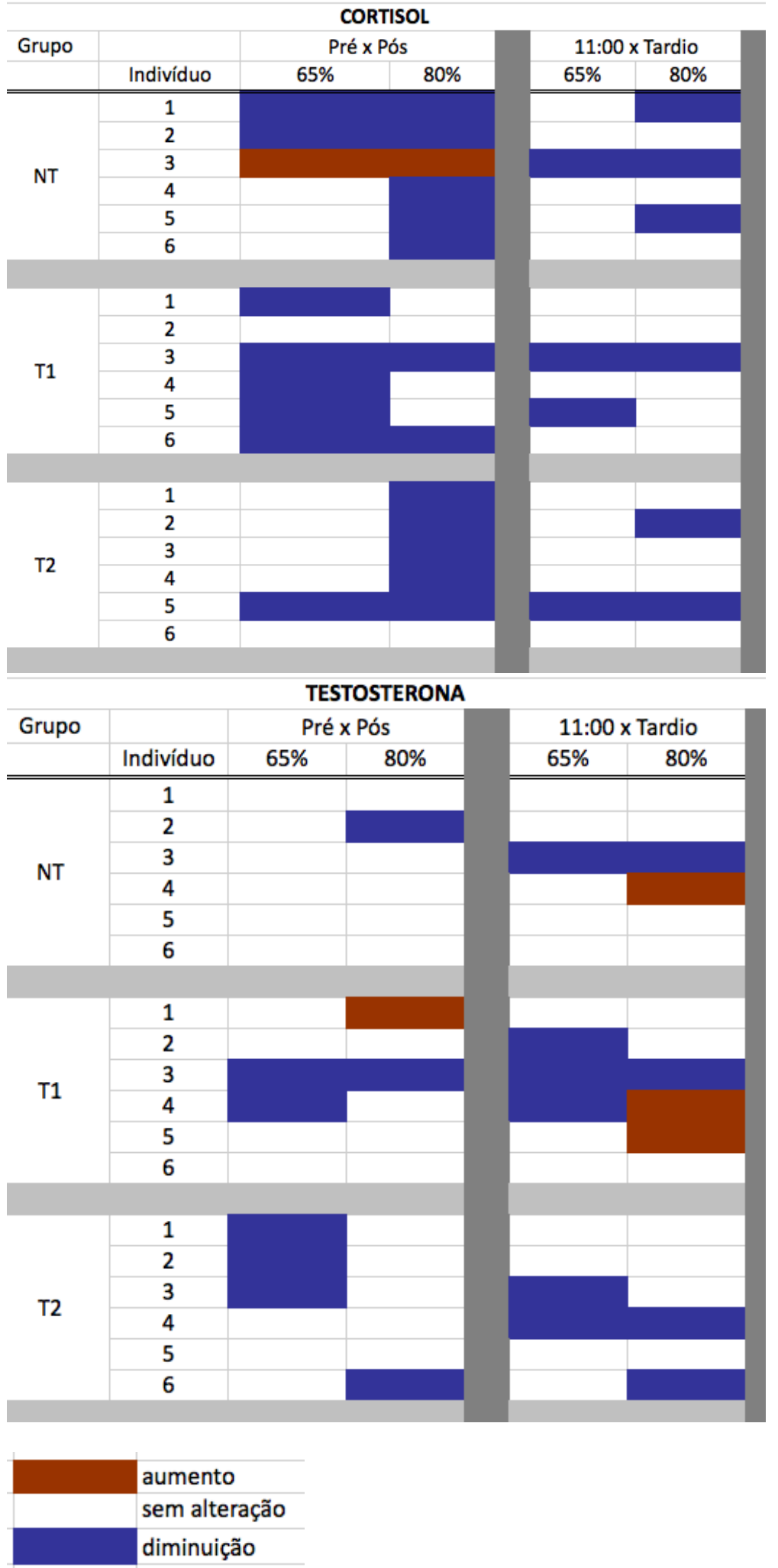

NT = não-treinados; T1 e T2 = treinados. Pré: corresponde aqui ao basal das 8 horas. Pós: pós-teste imediato. 11 horas: basal desse horário. Tardio: pós-teste tardio. Representação gráfica dos resultados individuais em termos de aumento/diminuição/não-alteração para cada um dos hormônios em cada um dos protocolos experimentais. 
As tabelas 5 e 6 apresentam os resultados que visam responder as Perguntas (0a) e (0b). Estes resultados são oriundos da comparação binomial, como descrito em 3.8.3.

Tabela 5 - Nível 1: há alteração?

\begin{tabular}{|l|c|c|c|c|}
\hline & \multicolumn{4}{|c|}{ CORTISOL } \\
\hline \multicolumn{4}{|c|}{ Pergunta (0a) } & \multicolumn{2}{c|}{ Pergunta (0b) } \\
\hline Grupo & $65 \%$ & $80 \%$ & $65 \%$ & $80 \%$ \\
\hline \hline NT & 0.656 & $\mathbf{0 . 0 1 6}$ & 0.109 & 0.656 \\
\hline T1 e T2 & 0.613 & 0.387 & 0.193 & 0.193 \\
\hline TODOS & 0.593 & $\mathbf{0 . 0 4 8}$ & 0.048 & 0.24 \\
\hline \multicolumn{5}{|c|}{ TESTOSTERONA } \\
\hline \multicolumn{5}{|c|}{ Prén x Pós } \\
\hline Grupo & $65 \%$ & $80 \%$ & $11: 00 \times$ Tardio \\
\hline \hline NT & 0.016 & 0.109 & $65 \%$ & $80 \%$ \\
\hline T1 e T2 & 0.806 & 0.073 & 0.109 & 0.343 \\
\hline TODOS & 0.015 & 0.015 & 0.118 & 0.387 \\
\hline
\end{tabular}

Significativo em haver alteração - passa ao Nível 2 Aleatoriedade na resposta (alteração e não alteração são indistintas de probabilidade 0,5 )

Significativo em não se alterar (i.e., a quantidade de não alterações é significativamente diferente da aleatoriedade)

NT = não-treinados; T1 e T2 = treinados.

Tabela 6 - Nível 2: há aumento?

\begin{tabular}{|l|c|c|c|c|}
\hline & \multicolumn{4}{|c|}{ CORTISOL } \\
\hline & \multicolumn{2}{|c|}{ Pergunta (0a) } & \multicolumn{2}{|c|}{ Pergunta (0b) } \\
\hline Grupo & \multicolumn{2}{|c|}{ Pré x Pós } & \multicolumn{2}{|c|}{$11: 00 \times$ Tardio } \\
\hline \hline NT & $65 \%$ & $80 \%$ & $65 \%$ & $80 \%$ \\
\hline T1 e T2 & & $0.109(\#)$ & & \\
\hline TODOS & & & & \\
\hline
\end{tabular}

TESTOSTERONA

\begin{tabular}{|l|c|c|c|c|}
\hline & \multicolumn{2}{|c|}{ Pergunta (0a) } & \multicolumn{2}{c|}{ Pergunta (Ob) } \\
\hline \multicolumn{4}{|c|}{ Pré x Pós } & \multicolumn{2}{c|}{$11: 00$ x Tardio } \\
\hline Grupo & $65 \%$ & $80 \%$ & $65 \%$ & $80 \%$ \\
\hline \hline NT & & & & \\
\hline T1 e T2 & & & & \\
\hline TODOS & & & & \\
\hline
\end{tabular}

Diminuição significativa

\begin{tabular}{|l|l|}
\hline (\#) & 5 diminuições em 6 individuos \\
\hline (\#\#) & 12 diminuições em 13 individuos \\
\hline
\end{tabular}

NT = não-treinados; T1 e T2 = treinados.

Referente às tabelas 5 e 6 , temos abaixo resumidamente algumas conclusões em relação ao comportamento do cortisol e da testosterona: 
Pré-teste versus pós-teste imediato (NT, T1 e T2):

Nível 1. Cortisol (T1 e T2) em $\mathrm{FCT}_{65}$ e $\mathrm{FCT}_{80}$ : comportamento aleatório.

Testosterona (T1 e T2) em $\mathrm{FCT}_{65}$ e $\mathrm{FCT}_{80}$ : comportamento aleatório.

Cortisol (NT) em $\mathrm{FCT}_{65}$ : comportamento aleatório. Em $\mathrm{FCT}_{80}$ : cortisol se altera.

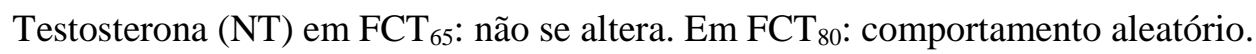

Nível 2. Cortisol em $\mathrm{FCT}_{80}$ (o cortisol aumenta o diminui?): aumentar e diminuir aleatório.

Pré-teste versus pós-teste imediato (todos os voluntários sem distinção entre grupos):

Nível 1. Cortisol (todos) em $\mathrm{FCT}_{65}$ : comportamento aleatório. Em $\mathrm{FCT}_{80}$ : cortisol se altera.

Testosterona (todos) em $\mathrm{FCT}_{65}$ e $\mathrm{FCT}_{80}$ : não se altera.

Nível 2. Cortisol em $\mathrm{FCT}_{80}$ (o cortisol aumenta o diminui?): o cortisol tem tendência a diminuir.

Basal da 11:00 versus pós-teste tardio (NT, T1 e T2):

Nível 1. Cortisol (T1 e T2) em $\mathrm{FCT}_{65}$ e $\mathrm{FCT}_{80}$ : comportamento aleatório.

Testosterona (T1 e T2) em $\mathrm{FCT}_{65}$ e $\mathrm{FCT}_{80}$ : comportamento aleatório.

Cortisol (NT) em $\mathrm{FCT}_{65}$ e $\mathrm{FCT}_{80}$ : comportamento aleatório.

Testosterona (NT) em $\mathrm{FCT}_{65}$ e $\mathrm{FCT}_{80}$ : comportamento aleatório.

Basal da 11:00 versus pós-teste tardio (todos os voluntários sem distinção entre grupos):

Nível 1. Cortisol (todos) em $\mathrm{FCT}_{65}$ : cortisol não se altera. Em $\mathrm{FCT}_{80}$ : comportamento aleatório.

Testosterona (todos) em $\mathrm{FCT}_{65}$ e $\mathrm{FCT}_{80}$ : comportamento aleatório.

Dessas conclusões referentes às tabelas 5 e 6 é importante detalhar a diferença entre "aleatoriedade na resposta" e "não alteração". No caso de aleatoriedade, os eventos “alteração" e "não-alteração" são igualmente prováveis de ocorrer, ou seja, conclui-se que não há um padrão de resposta. No caso de "não-alteração" significativa, o evento "não-alteração" se mostra mais provável de ocorrer, ou seja, conclui-se que há um padrão de não alteração.

A tabela 7 apresenta os p-valores das comparações diretas (descritas em 3.8.3) que visam responder a Pergunta (1). 
Tabela 7 - P-valores referente às perguntas descritas em 3.8.3.

\begin{tabular}{l|l|l}
\multicolumn{3}{l}{ Pergunta (1) } \\
\hline & $\mathrm{I}_{65} \times \mathrm{Ta}_{65}$ & $\mathrm{I}_{80} \times \mathrm{Ta}_{80}$ \\
\hline $\mathrm{NT}$ & 0,7072 & 0,6344 \\
\hline $\mathrm{T} 1$ & 0,5809 & 0,3756 \\
\hline $\mathrm{T} 2$ & 0,094 & 0,1175 \\
\hline TODOS & 0,4918 & 0,5946
\end{tabular}

\begin{tabular}{l|l|l} 
& \multicolumn{2}{l}{ Pergunta (2) } \\
\hline & $\mathrm{I}_{65} \times \mathrm{I}_{80}$ & $\mathrm{Ta}_{65} \times \mathrm{Ta}_{80}$ \\
\hline NT & 0,7486 & 0,614 \\
\hline $\mathrm{T} 1$ & 0,4017 & 0,3184 \\
\hline T2 & 0,1731 & 0,2544 \\
\hline TODOS & 0,1152 & 0,6887
\end{tabular}

Pergunta (3)

\begin{tabular}{l|l|l|l}
\hline $\mathrm{I}_{\mathrm{T} 1,65} \mathrm{xI}_{\mathrm{T} 2,65}$ & $\mathrm{Ta}_{\mathrm{T} 1,65} \times \mathrm{Ta}_{\mathrm{T} 2,65}$ & $\mathrm{I}_{\mathrm{T} 1,80} \mathrm{xI}_{\mathrm{T} 2,80}$ & $\mathrm{Ta}_{\mathrm{T} 1,80} \times \mathrm{Ta}_{\mathrm{T} 2,80}$ \\
\hline 0,3451 & 0,0221 & 0,1541 & 0,8653
\end{tabular}

\section{Pergunta (4)}

\begin{tabular}{l|l|l|l}
\hline $\mathrm{I}_{\mathrm{T} 1,65} \times \mathrm{I}_{\mathrm{NT}, 65}$ & $\mathrm{Ta}_{\mathrm{T} 1,65} \times \mathrm{Ta}_{\mathrm{NT}, 65}$ & $\mathrm{I}_{\mathrm{T} 1,80} \times \mathrm{I}_{\mathrm{NT}, 80}$ & $\mathrm{Ta}_{\mathrm{T} 1,80} \times \mathrm{Ta}_{\mathrm{NT}, 80}$ \\
\hline 0,9405 & 0,4706 & 0,3407 & 0,3407
\end{tabular}

I = índice de variação imediata. Ta = índice de variação tardia. 65 e 80 corresponde à potência de corrida. NT = não-treinados. T1 e T2 = treinados. Comparações diretas (descritas em 3.8.3) que visam responder a Pergunta (1). Note a diferença significativa entre as médias das variações tardias entre T1 e $\mathrm{T} 2\left(\mathrm{Ta}_{\mathrm{T} 1,65} \times \mathrm{Ta}_{\mathrm{T} 2,65}\right)$. 


\section{$\underline{V}$ - Discussão}

Começaremos a discussão desse estudo com foco nas perguntas propostas em Materiais e Métodos (perguntas 0, 1,2,3 e 4), seção 3.8. Posteriormente seguiremos com uma discussão mais ampla dos resultados obtidos.

\section{1 - Discussão direcionada às perguntas do estudo}

Perguntas (0)

Não-treinados (NT)

Em não-treinados, tomando-se as variações do cortisol isoladamente, houve queda em cinco dos seis voluntários após a corrida em $\mathrm{FCT}_{80}$, e aumento em um voluntário. Dessa forma, pela comparação binomial, o cortisol se alterou respondendo à questão 1 da seção 3.8.3. Já respondendo à questão 2 da seção 3.8 .3 (se houve aumento o diminuição), tal diminuição de 5 voluntários em 6 não foi significativa. Mesmo assim, comparando as respostas pré versus pós de corridas em $\mathrm{FCT}_{65}$ e $\mathrm{FCT}_{80}$, parece que o estímulo físico mais intenso, em desacordo com a maioria dos estudos, se associou mais à queda do cortisol do que com o aumento deste hormônio nesse período de tempo. Já comparando o pós-teste tardio ao basal das 11 horas, o cortisol teve comportamento aleatório em relação às corridas em FCT $_{65}$ e em FCT $_{80}$. Assim, mesmo com as alterações do cortisol no pós-teste imediato em $\mathrm{FCT}_{80}$, o reflexo tardio dessa sessão de corrida é uma aleatoriedade. A testosterona não se alterou em corridas em $\mathrm{FCT}_{65}$ (pré versus pós) e teve comportamento aleatório em $\mathrm{FCT}_{80}$ (pré versus pós). Teve também comportamento aleatório em $\mathrm{FCT}_{65}$ e $\mathrm{FCT}_{80}$ (11 horas versus tardio).

Treinados (T1 e T2)

Observando, separadamente, o cortisol e a testosterona (pré versus pós) e (11 horas versus tardio), tanto o cortisol quanto a testosterona em $\mathrm{FCT}_{65}$ e $\mathrm{FCT}_{80}$ tiveram comportamento aleatório em ambos os grupos (ver tabela 5).

\section{Todos os indivíduos sem distinção entre grupos}

A queda do cortisol também ocorreu quando se tomaram todos os voluntários (NT, T1 e T2) como um único grupo nas corridas em $\mathrm{FCT}_{80}$ (de acordo com a comparação binomial). Sob o ponto de vista desta análise, o cortisol se alterou, mostrando tendência a diminuir no pós-teste imediato em relação ao basal das 08:00 da manhã. A testosterona não se alterou em análise (pré versus pós) de corridas em $\mathrm{FCT}_{65}$ e FCT 80 e teve comportamento aleatório (11 horas versus tardio) em $\mathrm{FCT}_{65}$ e $\mathrm{FCT}_{80}$. 
Pergunta (1)

Não-treinados (NT)

No que se refere aos não-treinados, não se observou diferença significativa entre os índices de variação imediata (I) e tardia (Ta), tanto em $\mathrm{FCT}_{65}$ quanto em $\mathrm{FCT}_{80}$. Assim, nesse grupo, não foi possível observar um componente bifásico da razão T/C. Os gráficos das figuras 11 e 12 da seção 4.2 mostram como as razões T/C se comportaram nos dias de corrida em cada indivíduo. Retomando as hipóteses específicas de trabalho (seção 2.2), não foi possível observar uma alteração aguda significativa na razão T/C tanto no pós-teste imediato como no pós-teste tardio. Apesar desses resultados obtidos pela comparação direta, de acordo com a comparação binomial, o cortisol teve tendência a diminuir agudamente em FCT 80 (pré versus pós) e a testosterona teve comportamento aleatório ( $\mathrm{FCT}_{80}$ - pré versus pós). Isso contrasta com a hipótese descrita na introdução de um componente bifásico associando o exercício físico ao eixo hipofisário-gonadal. Segundo essa hipótese, o exercício físico poderia exercer, em uma primeira fase, um estímulo positivo neste eixo (resultando em aumento da testosterona) e, em uma fase tardia, um efeito negativo (com diminuição da testosterona). O cortisol poderia participar desse processo uma vez que poderia aumentar agudamente e permanecer aumentado por certo período de tempo ou aumentar subagudamente, exercendo enfim o suposto efeito inibitório direto sobre o eixo HHG. Nos resultados das amostras do pós-teste tardio, também não se observou tal fenômeno já que pelas análises binomiais o cortisol e a testosterona tiveram comportamento aleatório $\left(\mathrm{FCT}_{80}-11: 00\right.$ versus tardio).

\section{Treinados (T1 e T2)}

Nos grupos T1 e T2 também não se observou diferença significativa entre os índices de variação imediata e tardia, tanto em $\mathrm{FCT}_{65}$ quanto em $\mathrm{FCT}_{80}$. Assim, também neste grupo, não foi possível observar um componente bifásico da razão T/C. No grupo T2 em $\mathrm{FCT}_{65}$, embora as médias da variação imediata e tardia tenham sido semelhantes, tais médias se distanciaram mais do que nos outros grupos (p-valor $=0,094)$. Esses eventos (T2 em $\mathrm{FCT}_{65}$ ) foram, justamente, os que tiveram maior duração média (45 \pm 4 minutos). Isto vem a sugerir que o fator temporal pode ser importante nas alterações destes hormônios em resposta ao exercício físico. 
Todos os indivíduos sem distinção entre grupos

Não se observou diferença significativa entre os índices de variação imediata (I) e tardia (Ta), tanto em $\mathrm{FCT}_{65}$ quanto em $\mathrm{FCT}_{80}$, analisando todos os indivíduos como um único grupo.

Pergunta (2)

Não-treinados (NT)

Em relação ao efeito da intensidade do exercício físico, as variações imediatas ( $\mathrm{I}_{65}$ versus $\mathrm{I}_{80}$ ) e as variações tardias (Ta65 versus $\mathrm{Ta}_{80}$ ) mostraram-se estatisticamente semelhantes.

\section{Treinados (T1 e T2)}

No grupo dos treinados, resultados semelhantes ao grupo dos NT foram obtidos (i.e., médias estatisticamente semelhantes).

Todos os indivíduos sem distinção entre grupos

Analisando todos os indivíduos como um único grupo, também não se observaram diferenças significativas entre as medias imediatas e tardias.

\section{Pergunta (3)}

Em relação ao efeito do tempo versus efeito da demanda total, observou-se uma diferença significativa entre as médias das variações tardias entre T1 e T2 (TaT1,65 X Тат2,65). As variações tardias em T2 parecem ter sido maiores do que em T1. Em ambos os grupos, as potências no exercício foram semelhantes, mas o grupo T1 correu por trinta minutos (tempo fixo) e o grupo $\mathrm{T} 2$ teve diferentes tempos de corrida (gasto energético total fixo; 6300 batimentos cardíacos). Essa maior variação hormonal, porém, não teve um padrão identificável observando-se separadamente cada hormônio (ver tabela 4). Na tabela 4, podemos ver que houve mais "não alterações" do que "diminuições" em ambos os hormônios (na comparação 11:00 x Tardio em FCT65, tanto em T1 quanto em T2). As respostas individuais nessas sessões de corrida podem ser vistas nas figuras 13 e 15 da seção 4.2.

\section{Pergunta (4)}

Em relação ao efeito do pré-condicionamento ao exercício físico, não se observaram diferenças significativas entre as médias das variações entre os treinados e os nãotreinados nas diversas comparações (IT1,65 x I NT,65; TaT1,65 x Ta NT,65; IT1,80 x I NT,80; 
$\mathrm{Ta}_{\mathrm{T} 1,80} \times \mathrm{Ta}$ NT,80). Retomando as hipóteses específicas de trabalho (seção 2.2), as respostas da razão T/C em nosso estudo não parecem representar um marcador de estado de treinamento diferenciando treinados e não-treinados.

\section{2 - Discussão geral sobre os resultados}

Os resultados obtidos na presente pesquisa sugerem que não haja grandes variações do cortisol e da testosterona em resposta às sessões de corrida em $\mathrm{FCT}_{65}$ e $\mathrm{FCT}_{80}$, seja em homens treinados seja em não-treinados, em eventos de trinta minutos. $\mathrm{O}$ mesmo foi observado no grupo de treinados (T2) que tiveram corridas com maior duração: média de $41( \pm 3,5)$ minutos em $\mathrm{FCT}_{80}$ e $45( \pm 4)$ minutos em $\mathrm{FCT}_{65}$

Estes resultados são discordantes de várias pesquisas já feitas (e.g., Fahrner, 1998. Brownlee, 2005. Vuorimaa, 2008). São, contudo, semelhantes a alguns estudos que não observaram alterações importantes tanto na testosterona como no cortisol decorrentes do exercício físico agudo de resistência (Jacks et al., 2002; Hayes et al., 2015).

Como dito logo acima, estudos com achados discordantes aos nossos encontraram aumentos do cortisol após exercício físico agudo de corrida principalmente com tempos de corrida maiores do que 40 minutos (Fahrner, 1998. Brownlee, 2005. Vuorimaa, 2008). Trembley (2005) porém, só encontrou aumentos significativos do

cortisol após 120 minutos de corrida a $55 \%$ do $\dot{\mathrm{V}}_{2 \max }$ em corredores treinados (em contraste com corridas de 40 e 80 minutos). Bloom et al. (1976), comparando as respostas do cortisol a sessões de exercício físico em cicloergômetro em treinados e não-treinados, observaram quedas iniciais do cortisol até os 16 minutos de atividade com aumentos subsequentes do hormônio após 20 minutos de exercício com intensidades crescentes. Os aumentos do hormônio no plasma ocorreram tanto em treinados como em não-treinados, porém de forma mais intensa nos treinados. Hill et al. (2008) avaliaram as respostas do cortisol em homens moderadamente treinados a sessões de exercício físico de trinta minutos em cicloergômetro em diferentes intensidades (40, 60, e $80 \%$ do $\dot{\mathrm{V}}_{2 \max }$ ). Os autores observaram aumentos do cortisol após exercício nas intensidades de 60 e $80 \%$, porém, em 40\%, observaram queda do hormônio mesmo levando em consideração os ritmos circadianos. Jacks et al. (2002) 
avaliaram as respostas do cortisol salivar em sessões de 60 minutos de exercício físico em cicloergômetro em três intensidades $\left(44,5 ; 62,3\right.$ e $76 \%$ do $\left.\dot{\mathrm{V}}_{2 \max }\right)$. Nesse estudo, o cortisol médio dos participantes (10 homens ativos não-treinados) caiu nas intensidades baixas e moderadas e subiu na intensidade alta.

Este achado contrasta muito com nossos resultados uma vez que o grupo de nãotreinados apresentou queda do cortisol mais consistente na intensidade mais alta (FCT 80 ). Porém, os achados do estudo de Jacks et al. (2002), mostram que pode haver grandes variações na resposta desse hormônio de acordo com a intensidade dos exercícios físicos. Além disso, nesse estudo, em que se dosou o cortisol em 5 momentos durante o exercício e após 20 minutos do término deste, nas amostras dos 40 minutos de exercício, em nenhuma das intensidades se observaram alterações significativas do cortisol. Em nosso estudo, que teve sessões de corrida que variaram de 30 a 53 minutos (tabela 2), notou-se, analisando todos os indivíduos como um único grupo, a tendência do cortisol a diminuir em $\mathrm{FCT}_{80}$ no pós-teste imediato.

O metabolismo aeróbio continua aumentado na recuperação posterior ao exercício físico agudo, devido à depleção de fosfatos de alta energia ocorrida. A manutenção desse consumo de oxigênio elevado em relação ao repouso relaciona-se à duração e à intensidade do exercício (McArdle; Katch; Katch, 2007). Como exemplo, o consumo de oxigênio medido durante período de recuperação de 3 horas em mulheres treinadas que caminharam em esteira a $70 \%$ do $\dot{\mathrm{V}} \mathrm{V}_{2 \max }$ por 20, 40 e 60 minutos, foi de 8,6; 9,8; e 15,2 $\mathrm{L}_{\text {de }} \mathrm{O}_{2}$ por minuto, respectivamente (De Quinn, 1994). Acredita-se que o cortisol tenha papel importante neste período de recuperação pós-exercício na mobilização de fontes energéticas (Hill et al., 2008). Assim, no presente estudo, também buscou-se observar esta dinâmica do cortisol no tempo, na medida em que tal hormônio poderia apresentar um aumento tardio frente a uma sessão curta de exercício físico. Contudo, tal resultado não foi constatado.

Em relação à resposta da testosterona ao exercício aeróbio com intensidade submáxima, Hoffman (2014), já mencionado na Introdução (1.2) e em Material e Métodos (3.1), reunindo vários estudos, observou uma resposta bifásica deste hormônio, com aumento em exercícios de menor duração (> 20 min. e $<2$ horas e 
trinta minutos) e diminuição em exercícios com duração maior do que 3 horas. A partir deste pressuposto, o presente estudo buscou constatar se tal fenômeno poderia ocorrer a partir de sessões de corrida mais curtas, observando-se a dinâmica da testosterona salivar ao longo do tempo [com coletas pré-teste, pós-teste e pós-teste tardia (cerca de $2 \mathrm{~h}$ e $45 \mathrm{~min}$ após o término do exercício)]. Tal dinâmica da testosterona poderia, dependendo da dinâmica do cortisol, causar uma resposta bifásica na razão T/C. Como os dois hormônios possuem variações circadianas, foi importante o estabelecimento de horários fixos para os testes para permitir as análises. Contudo, não foi observado, em nosso estudo, o aumento da testosterona descrito por Hoffman, citado logo acima. Tampouco se observou uma queda tardia consistente da testosterona após as sessões de corrida, já que pela comparação binomial (pós-teste tardio versus basal das 11 horas), a testosterona teve comportamento aleatório.

Em meta-análise recente que avaliou estudos sobre as alterações do cortisol e testosterona salivares em resposta a eventos agudos de exercício físico (Hayes et al., 2015), concluiu-se que as concentrações de testosterona salivar tendem a aumentar em resposta ao exercício físico de resistência e de força, porém com grande variação nas amplitudes de resposta. A resposta do cortisol salivar também foi de aumento, tanto nos exercícios de força quanto nos aeróbios, sendo observada, ainda, grande variação nas amplitudes de resposta em função dos protocolos utilizados. Quanto à razão $\mathrm{T} / \mathrm{C}$, nos estudos que avaliaram exercícios de força, não houve alterações significativas nos valores pré e pós-exercício (tempo médio dos exercícios $=31,5$ min). Contudo, esta meta-análise salienta que os tempos de coletas hormonais causaram viés importante na direção da alteração da testosterona salivar.

\section{3 - Hipótese do hormônio livre}

A "hipótese do hormônio livre" formulada por Mendel (1989; 1992) afirma que a concentração intracelular de determinados hormônios, e, por conseguinte, o nível de atividade biológica invocada por esses hormônios, seria determinada apenas pela fração livre desses hormônios no plasma.

Segundo a hipótese do hormônio livre, em condições de ativação do "eixo do estresse" com consequente aumento dos níveis de glicocorticóides, o cortisol excederia a capacidade de ligação da CBG, proporcionando um estado com altos 
níveis da fração ativa deste hormônio. De um ponto de vista crônico, o resultado de uma ativação constante do "eixo do estresse" poderia ser deletéria, por exemplo causando supressão da resposta imune e inflamatória assim como supressão da reprodução (Desantis, 2011. Sapolsky, 2002).

Em nosso estudo, de uma forma geral, de maneira contrária à grande parte das pesquisas, ocorreram mais diminuições do cortisol livre após as corridas do que aumentos. De forma curiosa, no grupo dos não-treinados, a queda mais consistente deste hormônio ocorreu mediante à corrida em $\mathrm{FCT}_{80}$, ou seja, a de maior potência desenvolvida. A queda no cortisol poderia ser explicada por uma diminuição de sua síntese, por uma maior ligação do hormônio às proteínas plasmáticas ou por aumento de sua taxa de metabolização. A maioria dos estudos associa o exercício físico ao estímulo aumentado à secreção do ACTH com subsequente estímulo à secreção do cortisol. Hill et al. (2008) em trabalho que avaliou diferentes intensidades de exercício físico ligadas a alterações do cortisol, corroborou a hipótese de que exercícios de intensidade moderada a alta $\left(60 \%, 80 \%\right.$ do $\left.\dot{\mathrm{V}} \mathrm{O}_{2 \max }\right)$ provocam aumentos significativos no cortisol, sugerindo que nessas intensidades tanto haveria um estímulo aumentado à secreção do hormônio como haveria um componente da hemoconcentração sanguínea (nesse estudo, avaliou-se o cortisol total plasmático). Nesse caso, os autores sugerem que as elevações se devem ao aumento do estímulo do eixo HHA e que não há aumento na taxa de clearance metabólico do hormônio. No caso da queda do cortisol mediante exercício a $40 \%$ do $\dot{\mathrm{V}} \mathrm{O}_{2 \max }$, os autores sugerem que haja um aumento da taxa de clearance metabólico com maior absorção pelos tecidos-alvo do hormônio.

\section{4 - Ritmos circadianos}

Existem estudos que buscaram avaliar os horários do dia mais adequados para a prática de exercício físico do ponto de vista das respostas hormonais. Hakkinen e Pakarinen (1991) sugeriram que as respostas de elevação da testosterona em exercícios de força são mais acentuadas no final da tarde, embora os níveis naturais deste hormônio sejam mais baixos nesse período do dia. Sugerem, ainda, que os exercícios de força realizados à tarde possam se associar a um melhor ajuste muscular, atribuído à resposta de hormônios anabólicos como a testosterona. Autores 
também sugerem que prescrições individualizadas de exercícios físicos de força e de resistência baseados nas respostas da testosterona são uma estratégia válida na busca por melhores ajustes musculares (Beaven et al. 2008).

Em nosso estudo, os protocolos experimentais escolhidos não se associaram a alterações importantes dos ritmos circadianos naturais tanto do cortisol quanto da testosterona. Mesmo tendo sido feita associação das corridas em $\mathrm{FCT}_{80} \mathrm{com}$ quedas mais consistentes deste hormônio logo após o exercício físico, essas quedas não ocorreram tardiamente. Assim, as quedas observadas do cortisol após as corridas podem refletir, apenas, o ritmo natural deste hormônio, que tende a diminuir no decorrer do dia.

\section{VI - Conclusões}

1. O presente protocolo experimental não mostrou alterações consistentes nas concentrações de testosterona e de cortisol.

2. No presente protocolo experimental, a razão T/C se mostrou inadequada para se estimar o grau de esforço físico.

3. No presente protocolo experimental, a variância inerente aos hormônios estudados, limitou o uso destes como marcadores adequados do estado de treinamento físico. 


\section{VII - Resumo}

Fatores físico e psicológico estão associados a alterações de perfil hormonal. Desde a clássica reação de lutar-ou-fugir até sutis relações de dominância em grupos, observam-se variações em conjuntos de hormônios específicos. As variações hormonais relacionadas à prática de exercício físico tem sido foco de muitas pesquisas nas áreas da fisiologia e da saúde. Embora na maioria das vezes o exercício físico seja benéfico para a saúde, tal atividade pode gerar malefícios tanto em homens como em mulheres. Não é completamente conhecido em que nível o exercício físico cessa seus efeitos benéficos e começa a prejudicar o estado de saúde. Em busca desse suposto ponto de viragem, vários marcadores foram apresentados nas últimas décadas. Um destes marcadores é a razão entre a testosterona, considerada um hormônio anabólico, e cortisol, considerado um hormônio catabólico. Um desbalanço entre as alças consideradas anabólicas e as alças catabólicas do metabolismo pode se associar a certos componentes do exercício físico (por exemplo volume de treinamento e intensidade de treinamento) que podem ser monitorados na busca por um bom desempenho esportivo evitando-se efeitos deletérios da atividade. O presente projeto visou avaliar como o perfil anabólico/catabólico hormonal se comporta agudamente após exercício físico agudo, tendo em vista dados contraditórios presentes na literatura. Nesse contexto sessões de corrida em esteira em zonas de treinamento distintas foram realizadas em 6 voluntários não-treinados e 12 voluntários treinados para corridas de rua (subdivididos em T1 e T2). Segundo o protocolo experimental utilizado neste estudo, o exercício físico de corrida em intensidades moderada e intensa tanto em não-treinados como em treinados, pareceu não se associar a alterações significativas da dinâmica circadiana normal do cortisol e da testosterona. O cortisol teve tendência a diminuir logo após as corridas de alta intensidade com duração menor do que uma hora quando se observou todos os voluntários sem distinção entre treinados e não-treinados. Isso não ocorreu na coleta tardia após a corrida. Segundo este protocolo experimental, não se observou efeito catabólico tardio que poderia ter sido observado com queda da razão T/C tardia, com aumentos do cortisol e quedas da testosterona. Isto não quer dizer que tal efeito não possa ocorrer com protocolos diferentes que avaliem exercícios físicos de resistência com durações menores do que uma hora.

Palavras-chave: Razão testosterona / cortisol. Exercício físico agudo. 


\section{Abstract}

From the classic fight-or-flight reaction to subtle dominance relationships in groups, changes in specific hormones sets are observed. Physical and psychological factors are associated with these changes. Hormonal changes related to physical exercise have been focus of much research in the fields of physiology and health. Although often the exercise is beneficial to health, such activity can generate harmful effects in both men and women. It is not completely known at what level exercise ceases its beneficial effects and begins to harm the health. In search of that supposed turning point, several markers were presented in recent decades. One of these markers is the ratio between testosterone, which is considered an anabolic hormone, and cortisol, considered a catabolic hormone. An imbalance between the handles considered anabolic and the handles considered catabolic of the metabolism may be associated with certain components of the exercise (for example, training volume and intensity of training) that can be monitored in the search for a good sports performance avoiding deleterious effects of the activity. This project aimed to evaluate how the hormonal profile anabolic / catabolic behaves acutely after acute physical exercise in view of contradictory data present in the literature. In this context, running sessions on the treadmill at different training zones were held in 6 non-trained volunteers and 12 volunteers trained for street races (subdivided into T1 and T2). According to the experimental protocol used in this study, running exercise in moderate to high intensity in both untrained and trained men did not appear to be associated with significant changes of normal circadian dynamic of cortisol and testosterone. The cortisol tended to decrease after the exercises sessions with high intensity lasting less than an hour when it was observed all volunteers with no distinction between trained and untrained. That did not happen in the later hormonal collection after the running sessions. According to this experimental protocol, there was no late catabolic effect that could have been seen with falls of the late T/C ratio, with cortisol rises and falls of testosterone. This does not mean that such an effect cannot occur with different protocols that evaluate endurance exercise with shorter durations than an hour.

Keywords: Testosterone / cortisol ratio. Acute physical exercise. 


\section{VIII - Referências Bibliográficas:}

ADLERCREUTZ, H.; HARKONEN, M.; KUOPASSALMI, K.; KARVONEN, J. Effect of training on plasma anabolic and catabolic steroid hormones and their response during physical exercise. Int. J. Sports Med. v.7, p.27-28, 1986.

AMBROSI, F.; RIECI, S.; QUARTESAN,R.; MORETTI, P.; PELICEI, G.; PAGLIACCI, C.; NICOLETTI, I. Effects of acute benzodiazepine administration on growth hormone, prolactin and cortisol release after moderate insulin-induced hypoglycemia in normal women. Psychopharmacology. v.88, p.187-189, 1986.

AHTIAINEN, J.P.; PAKARINEN, A.; ALEN, M.; KRAEMER, W.J.; HÄKKINEN, K. Muscle hypertrophy, hormonal adaptations and strength development during strength training in strength-trained and untrained men. Eur. J. Appl. Physiol. v.89, p. 555-563, 2003.

ALMEIDA, S.A.; ANSELMO-FRANCI, J.A.; ROSA E SILVA, A.A.; CARVALHO, T.L. Chronic intermittent immobilization of male rats throughout sexual development: a stress protocol. Exp. Physiol. v.83, p.701-704, 1998.

ARAUJO, A.B.; DIXON, J.M.; SUAREZ, E.A.; MURAD, M.H.; GUEY, L.T.; WITTERT, G.A. Endogenous Testosterone and Mortality in Men: A Systematic Review and Meta-Analysis. J. Clin. Endocrinol. Metab. Oct, v.96, n.10, p.30073019, 2011.

BAMBINO, T.H.; HSUEH, A.J. Direct inhibitory effect of glucocorticoids upon testicular lutenizing hormone receptor and steroidogenesis in vivo and in vitro. Endocrinology. v.108, p.2142-2148, 1981.

BARBARINO, A.; DE MARINIS, L.; TOFANI, A.; DELLA CASA, S.; D'AMICO, C.; MANCINI, A.; CORSELlO, S.A.; SCIUTO, R.; BARINI, A. Corticotropin-releasing hormone inhibition of gonadotro- pin release and the effects of opioid blockade. J. Clin. Endocrinol. \& Metab. v.68, p.523-528, 1989. 
BEAVEN, C.M.; COOK, C.J.; GILL, N.D. Significant strength gains observed in rugby players after specific resistance exercise protocols based on individual salivary testosterone responses. J. Strength Cond. Res. V.22, n.2, p.419-425, 2008.

BLOOM, S.R.; JOHNSON, R.H.; PARK，D.M.; RENNIE， M.J.; SULAIMAN, W.R. Differences in the metabolic and hormonal response to exercise between racing cyclists and untrained individuals. Journal of Physiology. v.258, p.1-18, 1976.

BOBBERT, T.; MAI, K.; BRECHTEL， L.; SCHULTE， H.M.; WEGER, B.; PFEIFFER, A.F.; SPRANGER, J.; DIEDERICH, S. Leptin and endocrine parameters in marathon runners. Int. J. Sports Med. v.33, n.3, p.244-8, 2012.

BONIFAZI, M.; MENCARELLI, M.; FEDELE, V.; CECCARELLI, I.; PECORELli, A.; GRASSO, G.; ALOISI, A.M.; MUSCETTOLA, M.J. Glucocorticoid receptor mRNA expression in peripheral blood mononuclear cells in high trained compared to low trained athletes and untrained subjects. J. Endocrinol. Invest. v.32, n.10, p.816-20, 2009.

BORG, G.A.V.; NOBLE, B.J. Perceived exertion. In: WILMORE, J.H. (Editor). Exercise and Sport Sciences Reviews. New York: Academic Press, 1974. V.2, p. 131-53.

BOUdOU, P.; FIET, J.; LAUREAUX, C.; PATRICOT, M.C; GUEZENNEC, C.Y; FOGLIETTI, M.J.; VILLETTE, J.M.; FRIEMEL, F.; HAAG, J.C. Changes in several plasma and urinary components in marathon runners. Ann. Biol. Clin. (Paris). v.45, n.1, p.37-45, 1987.

BROWNLEE, K.K.; MOORE, A.W.; HACKNEY, A.C. Relationship between circulating cortisol and testosterone: influence of physical exercise. Journal of Sports Science and Medicine. v.4, p.76-83, 2005.

CARROLL, B.J.; CASSIDY, F.; NAFTOLOWITZ, D.; TATHAM, N.E; WILSON, W.H.; IRANMANESH, A.; LIU, P.Y.; VELDHUIS， J.D. 
Pathophysiology of hypercortisolism in depression. Acta Psychiatr. Scand. Suppl. v.433, p.90-103, 2007.

CASPERSEN, C.L.; POWELL, K.E.; CHRISTENSON, G.M. Physical activity, exercise, and physical fitness: definitions and distinctions for health-related research. Public Health Rep. v.100, n.2, p.126-131, 1985.

CHARPENET, G.; TACHE, Y.; BERNIER, M.; DUCHARME, J.R.; COLLU, R. Stress-induced testicular hyposensitivity to gonadotropin in rats: role of the pituitary gland. Biol. Reprod. v.27, p.616-623, 1982.

CHEN, M.D.; O’BYRNE, K.T.; CHIAPPINI, S.E.; HOTCHKISS, J.; KNOBIL, E. Hypoglycemic 'stress' and gonadotropin-releasing hormone pulse generator activity in the rhesus monkey: role of the ovary. Neuroendocrinology. v.56, p.666-673, 1992.

COOK, C.J.; BEAVEN, C.M. Salivary testosterone is related to self-selected training load in elite female athletes. Physiology \& Behavior. v.27, p.8-12, 2013.

CREWTHER, B.T., COOK, C.J., GAVIGLIO, C.M., KILDUFF, L.P., DRAWER, S. Baseline strength can influence the ability of salivary free testosterone to predict squat and sprinting performance. J. Strength Cond. Res. v.26, n.1, p.261-8 2012.

CREWTHER, B.T.; SANCTUARY, C.E.; KILDUFF, L.P.; CARRUTHERS, J.S.; GAVIGLIO, C.M.; COOK, C.J. The workout responses of salivary-free testosterone and cortisol concentrations and their association with the subsequent competition outcomes in professional rugby league. J. Strength Cond. Res. V.27, n.2, p.471-476, 2013. 
CUMMING, D.C.; QUIGLEY, M.E.; YEN, S.C. Acute suppression of circulating testosterone levels by cortisol in men. Journal of Clinical Endocrinology and Metabolism. v.57, p.671-673, 1983.

CUMMING, D.C.; BRUNSTING, L.A.; STRICH, G.; RIES, A.L.; REBAR, R.W. Reproductive hormone increases in response to acute exercise in men. Med. Sci. Sports Exerc. v.18,p.369-373, 1986.

DAVIES, C.T.; FEW, J.D. Effects of exercise on adrenocortical function. Journal of Applied Physiology. v.35, p.887-891, 1973.

DE QUINN, T.J.; VROMAN, N.B; KERTZER, R. Postexercise oxygen consumption in trained females: effect of exercise duration. Med. Sci. Sports Exerc. v.26, p.908, 1994.

DESANTIS, L. An examination of the free hormone hypothesis through phylogenetic comparison of glucocorticoid and corticosteroid-binding globulin levels among the vertebrates. 2011. Dissertação (mestrado) - Department of Ecology and Evolutionary Biology, University of Toronto, Toronto, 2011. Disponível em:<https://tspace.library.utoronto.ca/bitstream/1807/30571/4/Desantis_Lanna_M _201111_MSc_thesis.pdf>. Acesso em: 16 Mar. 2015.

DESSYPRIS, K.; KUOPPASALMI, K.; ADLERCREUTZ, H. Plasma cortisol, testosterone, androstenedione and luteinizing hormone ( $\mathrm{LH})$ in a noncompetitive marathon run. J. Steroid. Biochem. v.7, p.33-37, 1976.

DONOVAN, C.M.; SUMIDA, D.D. Training enhanced hepatic gluconeogenesis: the importance for glucose homeostasis during exercise. Med. Sci. Sports Exerc. v.29 p.628, 1997.

DUCLOS, M.; GUINOT, M.; LE BOUC, Y. Cortisol and GH: odd and controversial ideas. Appl. Physiol. Nutr. Metab. v.32, p.895-903, 2007. 
DUFAU, M,L.; TINAJERO, J.C.; FABBRI, A. Corticotropin-releasing factor: an antireproductive hormone of the testis. FASEB J. v.7, p.299-307, 1993.

DRINKWATER, B.L.; NILSON, K.; OTT, S.; CHESNUT, C.H.I.I.I. Bone mineral density after resumption of menses in amenorrheic athletes. JAMA. v.256, p.380-2, 1986.

FAHRNER, C.L., HACKNEY, A.C. Effects of endurance exercise on free testosterone concentration and the binding affinity of sex hormone binding globulin (SHBG). Int. J. Sports Med. v.19, n.1, p.12-5, 1998.

FABBRI, A.; TINAJERO, J.C.; DUFAU, M.L. Corticotropin-releasin factor is produced by rat Leydig cells and has a major local antireproductive role. Endocrinology. v.127, p.1541-1543, 1990.

FRANÇA, S.C.A.; NETO, T.L.B.; AGRESTA, M.C.; LOTUFO, R.F.M.; KATER, C.E. Divergent responses of serum testosterone and cortisol in athlete men after a marathon race. Arq Bras Endocrinol Metab v.50, n.6, p.1082-1087, 2006.

GALBO, H. Influence of aging and exercise on endocrine function. International Journal of Sports Nutrition and Exercise Metabolism suppl. v.11, p.49- 57, 2001.

GAMBACCIANI, M.; YEN, S.S.C.; RASMUSSEN, D. GnRH release from the medial basal hypothalamus: in vitro inhibition by corticotropin-releasing factor. Neuroendocrinology. v.43, p.533-536, 1986.

GLASS, S.; DWYER, G.B. ACSM's metabolic calculations handbook. Philadelphia: Lippincott Williams \& Wilkins, 2007.

GONZALEZ-ALONSO, J.; CALBET, J.A.; NIELSEN, B. Muscle blood flow is reduced with dehydration during prolonged exercise in humans. Journal of Physiology. v.513, p.895-905, 1998. 
GOUARNE， C.; GROUSSARD， C.; GRATAS-DELAMARCHE， A.; DELAMARCHE, P.; DUCLOS, M. Overnight urinary cortisol and cortisone add new insights into adaptation to training. Med. Sci. Sports Exerc. v.37, n.7, p.1157-67, 2005.

GREEN, H.J.; BURNETT, M.; KOLLIAS, H.; OUYANG, J.; SMITH, I.; TUPLING, S. Malleability of human skeletal muscle Na-K-ATPase pump with short term training. J Appl Physiol. v.97, p.143, 2004.

GREEN, J. A. The heart rate method for estimating metabolic rate: review and recommendations. Comparative Biochemistry and Physiology - Part A: Molecular \& Integrative Physiology, v.158, n.3, p.287-304, 2011.

HACKNEY, A.C.; VIRU, A. Twenty-four-hour cortisol response to multiple daily exercise sessions of moderate and high intensity. Clinical Physiology. v.19, p.178$182,1999$.

HAKKINEN, K.; PAKARINEN, A.; KYROLAINEN, H.; CHENG, S.; KIM, D.; KOMI, P. Neuromuscular adaptations and serum hormones in females during prolonged power training. Int. J. Sports Med. v.11, p.91-98, 1990.

HAKKINEN, K.; PAKARINEN, A. Serum hormones in male strength athletes during intensive short-term strength training. Eur. J. Appl. Physiol. Occup. Physiol. v.63, n3-4, p.194-199, 1991.

HAKKINEN, K.; PAKARINEN, A.; KRAEMER, W.J.; NEWTON, R.U.; ALEN, M. Basal concentrations and acute responses of serum hormones and strength development during heavy resistance training in middle-aged and elderly men and women. J. Gerontol. Ser. A. Biol. Sci. Med. Sci. v.55, p.95-105, 2000.

HAYES， L.D.; GRACE，F.M.; BAKER， J.S.; SCULTHORPE， N. Exerciseinduced responses in salivary testosterone, cortisol, and their ratios in men: a meta-analysis. Sports Med. v.45, n.5, p.713-726, 2015. 
HILL, E.E.; ZACK, E.; BATTAGLINI, C.; VIRU, M.; VIRU, A.; HACKNEY, A.C. Exercise and circulating cortisol levels: The intensity threshold effect. J. Endocrinol. Invest. v.31, p.1-5, 2008.

HOFFMAN, J. Physiological aspects of sport training and performance. 2.ed. Florida: Human Kinetics, 2014. p.26.

JACKS, D.E.; SOWASH, J.; ANNING, J.; MCGLOUGHLIN, T.; ANDRES, F. Effect of exercise at three exercise intensities on salivary cortisol. J. Strength Cond. Res. v.16, n.2, p.286-289, 2002.

JACKSON, A.S.; POLLOCK, M.L. Generalized equations for predicting body density of men. British Journal of Nutrition. v.40, p.497-504, 1978.

JEŽOVÁ, D.; VIGAŠ, M. Testosterone Response to Exercise during Blockade and Stimulation of Adrenergic Receptors in Man. Horm. Res. v.15, p.141-147, 1981.

KALANTARIDOU， S.N.; ZOUMAKIS， E.; MAKRIGIANNAKIS， A.; LAVASIDIS, L.G.; VREKOUSSIS, T.; CHROUSOS, G.P. Corticotropinreleasing hormone, stress and human reproduction: an update. Journal of Reproductive Immunology. v.85, p.33-39, 2010.

KARKOULIAS, K.; HABEOS, I.; CHAROKOPOS, N.; TSIAMITA, M.; MAZARAKIS, A.; POULI, A.; SPIROPOULOS, K. Hormonal responses to marathon running in non-elite athletes. European Journal of Internal Medicine. v.19, p.598-601, 2008.

KARVONEN, M.J.; KENTALA, E.; MUSTALA, O. The effects of training in heart rate. Ann. Med. Exp. Biol. Fenn.v.35, p.307, 1957. 
KERN, W.; PERRAS, B.; WODICK, R.; FEHM, H.L.; BORN, J. Hormonal secretion during nighttime sleep indicating stress of daytime exercise. J. Appl. Physiol. v.79, p.1461-1468, 1995.

KIESS, W.; PFAEFFLE, R. Análise de esteróides na saliva: uma ferramenta nãoinvasiva para pesquisa em pediatria e clínica médica. J. Pediatr. v.83, n.2, p.97-99, 2007.

KIRSCHNER, M.A.; BARDIN, C.W. Androgen production and metabolism in normal and virilized women. Metabolism. v.21, p.667-688, 1972.

KRAEMER， W.J.; GORDON， S.E.; FLECK, S.J.; MARCHITELLI, L.J.; MELLO， R.; DZIADOS， J.E.; FRIEDL， K.; HARMAN， E.; MARESH, C.; FRY, A.C. Endogenous anabolic hormonal and growth factor responses to heavy resistance exercise in males and females. Int. J. Sports Med. v.12, p.228235, 1991.

KRAEMER, W.J.; FLECK, S.J.; DZIADOS, J.E.; HARMAN, E.A.; MARCHITELLI, L.J.; GORDON， S.E.; MELLO, R.; FRYKMAN, P.N.; KOZIRIS, L.P.; TRIPLETT, N.T. Changes in hormonal concentrations after different heavy-resistance exercise protocols in women. J. Appl. Physiol. v.75, p.594-604, 1993.

LAFRENZ, A.J.; WINGO, J.E.; GANIO, M.S.; CURETON, K.J. Effect of ambient temperature on cardiovascular drift and maximal oxygen uptake. Med. Sci. Sports Exerc. v.40, n.6, p.1065-1071, 2008.

LU, S.S.; LAU, C.P.; TUNG, Y.; HUANG, S.W.; CHEN, Y.H.; SHIH, H.C.; TSAI, S.C.; LU, C.C.; WANG, S.W.; CHEN, J.J.; CHIEN, E.J.; CHIEN, C.H.; WANG, P.S. Lactate and the effects of exercise on testosterone secretion: evidence for the involvement of a cAMP-mediated mechanism. Medicine \& Science in Sports \& Exercise. v.29, n.8, p.1048-1054, 1997. 
LUGER, A.; DEUSTER, P.A.; KYLE, S.B.; GALLUCCI, W.T.; MONTGOMERY, L.C.; GOLD, P.W.; LORIAUX, D.L.; CHROUSOS, G.P. Acute hypothalamic-pituitary-adrenal responses to the stress of treadmill exercise. Physiologic adaptations to physical training. The New Engl. J. Med. v.316, n.21, p.1309-1315, 1987.

MARGARET, F.; MCCANCE, C.; MCCANCE, K.L.; HUETHER, S.E. 2014. Stress and disease. In: MCCANCE, K.L.; HUETHER, S.E. Pathophysiology The biologic basis for disease in adults and children. 7.ed. Canadá: Elsevier, 2014. p.347-348.

MARIC, D.; KOSTIC, T.; KOVACEVIC, R. Effects of acute and chronic immobilization stress on rat Leydig cell steroidogenesis. J. Steroid Biochem. Mol. Biol. v.58, p.351-355, 1996.

MCARDLE, W.D., KATCH, F.I., KATCH, V.L. Exercise physiology - Energy, Nutrition \& Human Performance. 6.ed. Baltimore: Lippincott Williams \& Wilkins, 2007.

MANN, D.R.; ORR, T.E. Effect of restraint stress on gonadal proopiomelanocortin peptides and the pituitary-testicular axis in rats. Life Sci. v.46, n.22, p.1601-1609, 1990.

MASTORAKOS, G.; PAVLATOU, M.; DIAMANTI-KANDARAKIS, E.; CHROUSOS, G.P. Exercise and the Stress System. Hormones. v.4, n.2, p.73-89, 2005.

MAYERHOFER, A.; STEGER, R.W.; GOW, G.; BARTKE, A. Catecholamines stimulate testicular testosterone release of the immature golden hamster via interaction with alpha- and beta-adrenergic receptors. Acta Endocrinol. (Copenh). v.127, n.6, p.526-530, 1992.

MEEUSEN, R.; PIACENTINI, M.F.; BUSSCHAERT, B.; BUYSE, L.; DE SCHUTTER, G.; STRAY-GUNDERSEN, J. Hormonal responses in athletes: the 
use of a two bout exercise protocol to detect subtle differences in (over)training status. Eur. J. Appl. Physiol. V.91, p.140-146, 2004.

MEEUSEN, R.; DUClOS, M.; FOSTER, C.; FRY, A.; GLEESON, M.; NIEMAN, D.; RAGLIN, J.; RIETJENS, G.; STEINACKER, J.; URHAUSEN, A. 2012. Prevention, Diagnosis, and Treatment of the Overtraining Syndrome: Joint Consensus Statement of the European College of Sport Science and the American College of Sports Medicine. Medicine \& Science in Sports \& Exercise. v.45, n.1, p.186-205, 2012.

MENDEL, C. M. The free hormone hypothesis: A physiologically based mathematical model. Endocr. Rev. v.10, n.3, p.232-274, 1989.

MENDEL, C. M. The free hormone hypothesis Distinction from the free hormone transport hypothesis. J. Androl. v.13, n.2, p.107-116, 1992.

MONTAIN, J.; COYLE, F. Influence of graded dehydration on hyperthermia and cardiovascular drift during exercise. Journal of Applied Physiology. v.73, p.13401350, 1992.

MORGAN, K.A. Salivary testosterone and cortisol measurements in professional elite rugby union players. Dissertação (Mestrado) - University of Glamorgan, 2009.

MORVILlE, R.; PESQIES, P.C.; GUEZZENEC, C.Y.; SERRURIER, B.C.; GUINARD, M. Plasma variation in testicular and adrenal androgens during prolonged physical exercise in man. Ann. Endocrinol. v.40, p.501-510, 1979.

NINDL, B.C.; KRAEMER, W.J.; GOTSHALK, L.A.; MARX, J,O.; VOLEK, J.S.; BUSH, F.A.; HÄKKINEN, K.; NEWTON, R.U.; FLECK, S.J. Testosterone responses after resistance exercise in women: influence of regional fat distribution. Int. J. Sport Nutr. Exerc. Metab. v.11, p.451-465, 2001. 
NUNES, L.A.S.; MACEDO, D.V. Saliva as a diagnostic fluid in sports medicine: potential and limitations. J. Bras. Patol. Med. Lab. v.49, n.4, p. 247-255, 2013 .

NORMAN, R.L. Effects of corticotropin-releasing hormone on luteinizing hormone, testosterone, and cortisol secretion in intact male rhesus macaques. Biol. Reprod. v.49, p.148-153, 1993.

OLSTER, D.H.; FERIN, M. Corticotropin-releasing hormone inhibits gonadotropin secretion in the ovariectomized rhesus monkey. J. Clin. Endocrinol. \& Metab. v.65, p.262-267, 1987.

ORR, T.E.; TAYLOR, M.F.; BHATTACHARYYA, A.K.; COLLINS, D.C.; MANN, D.R. Acute immobilization stress disrupts testicular steroidogenesis in adult male rats by inhibiting the activities of 17a-Hydroxylase and 17,20-Lyase without affecting the binding of LH/hCG receptors. Journal of Andrology. v.15, n.4, p.302-308, 1994.

OTIS, C.L.; DRINKWATER, B.; JOHNSON, MIMI, L.; ANNE, J.; WILMORE, J. A tríade da atleta: posicionamento oficial. Rev. Bras. Med. Esporte. v.5, n.4, p.150-158,1999

PASSAGLIA, D.G.; EMED, L.G.M.; BARBERATO, S.H.; GUERIOS, S.T.; MOSE, A.I.; SILVA, M.M.F.; ISHIE， E.; GUARITA-SOUZA， L.C.; COSTANTINI, C.R.F.; FARIA-NETO, J.R. Acute Effects of Prolonged Physical Exercise: Evaluation After a Twenty-Four-Hour Ultramarathon. Arq. Bras. Cardiol. 2012.

PATE, R.R., PRATT, M.; BLAIR, S.N.; HASKELL, W.L.; MACERA, C.A.; BOUCHARD, C.; BUCHNER, D.; ETTINGER, W.; HEATH, .G.W; KING, .A.C.; et al. Physical activity and public health - A recommendation from the Center for Disease Control and Prevention and the American College of Sports Medicine. JAMA. v.273, p.402-407, 1995. 
PETRAGliA, F.; SUTTON, S.; VAlE, W.; PlOTSKY, P. Corticotropinreleasing factor decreases plasma luteinizing hormone levels in female rats by inhibiting gonadotropin- releasing hormone release into hypophyseal portal circulation. Endocrinology. v.120, p.1083-1088, 1987.

PEVET, P.; CHALLET, E. Melatonin: Both master clock output and internal time-giver in the circadian clocks network. Journal of Physiology - Paris. v.105, p.170-182, 2011.

PHILLIPS, S.M. Strength and hypertrophy with resistance training: chasing a hormonal ghost. Eur. J. Appl. Physiol. v.112, p.1981-1983, 2011.

RAFF, H.; TRIVEDI, H. Circadian rhythm of salivary cortisol, plasma cortisol, and plasma ACTH in end-stage renal disease. Endocrine Connections. v.2, p.2331, 2013.

RIVIER, C.; RIVEST, S. Effect of stress on the activity of the hypothalamicpituitary-gonadal axis: peripheral and central mechanisms. Biol. Reprod. v.45, p.523-532, 1991.

ROWELL, L.; MURRAY, J.; BRENGELMANN, G.; KRANING, K. Human cardiovascular adjustments to rapid changes in skin temperature during exercise. Circulation Research. v.24, p.711-724, 1969.

SAKAKURA, M.; TAKEBE, K.; NAKAGAWA, S. Inhibition of luteinizing hormone secretion induced by synthetic LRH by long-term treatment with glucocorticoids in human subjects. J. Clin. Endocrinol. Metab. v.40, p.774-779, 1975.

SAPOLSKY, R. M. Neuroendocrinology of the stress-response. In BECKER, J.B. et al. Behavioral Endocrinology. 2.ed. Cambridge, Massachusetts: MIT Press, 2002. p.287-324. 
SIMÕES, H.G.; CAMPBELL, C.S.G.; BALDISSERA, V.; DENADAI, V.; KOKUBUN, E. Determination of the anaerobic threshold by blood lactate and glucose measurements in track tests for runners. Rev. Paul. Educ. Fís. v.12, p.1730, 1998.

SPEROFF, L.; GLASS, R.H.; KASE, N.G. Neuroendocrinology. In: SPEROFF, L.; GLASS, R.H.; KASE, N.G. Clinical Gynecologic Endocrinology and Infertility. Baltimore:Willians \& Wilkins, 1989. p.51-89.

SMITH, G.D.; BEN-SHLOMO, Y.; BESWICK, A.; YARNELL, J.; LIGHTMAN, S.; ELWOOD, P. Cortisol, testosterone, and coronary heart disease - prospective evidence from the Caerphilly study. Circulation. v.112, p.332-340, 2005.

STOJKOV, N.J.; JANJIC, M.M.; BJELIC, M.M.; MIHAJLOVIC, A.I.; KOSTIC, T.S.; ANDRIC, S.A. Repeated immobilization stress disturbed steroidogenic machineryand stimulated the expression of cAMP signaling elements and adrenergic receptors in Leydig cells. Am. J. Physiol. Endocrinol. Metab. v.302, p.1239-1251, 2012.

SUTTON, J.R.; COLEMAN, M.J.; CASEY, J.; LAZARUS, L. Androgen response during physical exercise. Br. Med. J. v.1, p.520-522, 1973.

TORPY, D. Hypotalamic-pituitary-adrenal axis and the female reproductive system. In: CHROUSOS, G.P. Moderator: Interactions between the hypothalamicpituitary-adrenal axis and the female reproductive system: clinical implications. Ann. Intern. Med. v.129, p.229-40, 1998.

TREMBLAY, M.S.; COPELAND, J.L.; VAN HELDER, W. Influence of exercise duration on post-exercise steroid hormone responses in trained males. Eur. J. Appl. Physiol. v.94, n.5-6, p.505-13, 2005.

URHAUSEN, A.; GABRIEL, H.; KINDERMANN, W. Blood hormones as markers of training stress and overtraining. Sports Med. v.20, p.251-276, 1995. 
URHAUSEN, A.; GABRIEL, H.; WEILER, B.; KINDERMANN, W. Ergometric and psychological findings during overtraining: a long-term follow-up study in endurance athletes. Int. J. Sports Med. v.19, p.114-120, 1998.

ULISSE, S.; FABBRI, A.; DUFAU, M. Corticotropin-releasing factor receptors and actions in rat leydig cells. J. Biol. Chem. v.264, p.2156-2163, 1989.

VERMEULEN, A.; VERDONCK, L.; KAUFMAN, J.M. A Critical Evaluation of Simple Methods for the Estimation of Free Testosterone in Serum. The Journal of Clinical Endocrinology \& Metabolism. V.84, n.10, p.3666-3672.

VERVOORN, C.; VERMULST, L.J.M.; BOELENS-QUIST, A.M.; KOPPESCHAAR, H.P.F.; ERICH, W.B.M.; THIJSSEN, J.H.H.; DE VRIES, W.R. Seasonal changes in performance and free testosterone: cortisol ratio of elite female rowers. Eur. J. Appl. Physiol. v.64, p.14-21, 1992.

VILLAS BÔAS, M.S. Comparação dos indicadores psicofisiológicos do estresse entre atletas de basquete adaptado e de basquete convencional em situação competitiva. 2013.Tese (Doutorado) - Setor de Ciências Biológicas, Universidade Federal do Paraná, Curitiba, 2013.

VINING, R.F.; MCGINLEY, R.A.; SYMONS, R.G. Hormones in saliva: mode of entry and consequent implications for clinical interpretation. Clin. Chem. v.29, n.10, p.1752-6, 1983.

VUORIMAA, T.; AHOTUPA, M.; HÄKKINEN, K.; VASANKARI, T. Different hormonal response to continuous and intermittent exercise in middle-distance and marathon runners. Scand. J. Med. Sci. Sports. v.18, n.5, p.565-72, 2008.

WEST, D.; KUJBIDA, G.; MOORE, D.R.; ATHERTON, P.; BURD, N.A.; PADZIK, J.P.; DE LISIO, M.; TANG, J.E.; PARISE， G.; RENNIE, M.J.; BAKER, S.K.; PHILLIPS, S.M. Resistance exercise-induced increases in putative anabolic hormones do not enhance muscle protein synthesis of 
intracellular signaling in young men. Journal of Physiology. v.587, n.21, p.52395247, 2009.

WEST, D.W.D.; PHILLIPS, S.M. Associations of exercise-induced hormone profiles and gains in strength and hypertrophy in a large cohort after weight training. Eur. J. Appl. Physiol. v.112, p.2693-2702, 2012.

WILKERSON, J.E.; HORVATH, S.M.; GUTIN, B. Plasma testosterone during treadmill exercise. Journal of Applied Physiology. v.49, p.249-253, 1980.

WINGO, J.E.; GANIO, M.S.; CURETON, K.J. Cardiovascular drift during heat stress: implications for exercise prescription. Exerc. Sport Sci. Rev. v.40, n.2, p.88-94, 2012.

WINGO, J.E.; SALAGA, L.J.; NEWLIN; M.K., CURETON, K.J. Cardiovascular drift and Vo2max during cycling and walking in a temperate environment. Aviat Space Environ. Med. v.83, n.7, p.660-666, 2012.

WITTERT, G. The effect of exercise on the hypothalamus-pituitary-adrenal axis. In: WARREN, M.P.; CONSTANTINI, N.W. Contemporary Endocrinology: Sports Endocrinology. Totowa: Humana Press, 2000. p.43-56.

WOLFE, R.R. Control of muscle protein breakdown: effects of activity and nutritional states. International Journal of Sports Nutrition and Exercise Metabolism Suppl. v.11, p.164-169, 2001.

WU, G.; FLYNN, N.E.; KNABE, D.A. Enhanced intestinal synthesis of polyamines from proline in cortisol-treated piglets. AM. J. Physiol. Endocrinol. Metab. v.279, p.395-402, 2000.

YOUNG, E.A.; AKIL, H. Corticotropin-releasing factor stimulation of adrenocorticotropin and beta-endorphin release: effects of acute and chronic stress. Endocrinology. v.117, p.23-30, 1985. 
ZSCHUCKE, E.; RENNEBERG, B.; DIMEO, F.; WÜSTENBERG, T.; STRÖHLE, A. The stress-buffering effect of acute exercise: evidence for HPA axis negative feedback. Psychoneuroendocrinology. v.51, p.414—425, 2015.

ZITZMANN, M.; NIESCHLAG, E.Testosterone levels in healthy men in relation to behavioral and physical characteristics: facts and constructs. European Journal of Endocrinology. v.144, p.183-197, 2001. 